\title{
Cloud Migration Research: A Systematic Review
}

\author{
Pooyan Jamshidi, Aakash Ahmad, and Claus Pahl, Member, IEEE
}

\begin{abstract}
By leveraging cloud services, organizations can deploy their software systems over a pool of resources. However, organizations heavily depend on their business-critical systems, which have been developed over long periods. These legacy applications are usually deployed on-premise. In recent years, research in cloud migration has been carried out. However, there is no secondary study to consolidate this research. This paper aims to identify, taxonomically classify and systematically compare existing research on cloud migration. We conducted a systematic literature review (SLR) of 23 selected studies, published from 2010 to 2013. We classified and compared the selected studies based on a characterization framework that we also introduce in this paper. The research synthesis results in a knowledge base of current solutions for legacy-to-cloud migration. This review also identifies research gaps and directions for future research. This review reveals that cloud migration research is still in early stages of maturity, but is advancing. It identifies the needs for a migration framework to help improving the maturity level and consequently trust into cloud migration. This review shows a lack of tool support to automate migration tasks. This study also identifies needs for architectural adaptation and self-adaptive cloud-enabled systems.
\end{abstract}

Index Terms-Cloud computing, cloud migration, legacy-tocloud migration, systematic literature review.

\section{INTRODUCTION}

$\mathrm{C}$ ILOUD COMPUTING has recently been the focus of attention in computing both as academic research and in industrial initiatives [1]. Major IT companies and start-ups see cloud computing as an opportunistic business strategy to remain competitive and to meet business objectives [1] [2] [3]. Larger enterprises are trying to exploit the benefits of this platform [4] by taking business continuity strategies into account [1]. For the former category, the attraction comes from the costing flexibility favoring pay-per-use models rather than upfront purchase of an overprovisioned infrastructure. Scalability, reliability and interoperability of cloud environments are also appealing [5] [4]. Many organizations still rely on so-called legacy systems - software developed over the lifetime of an organization using traditional development methods [6]. Despite maintainability issues, on-premise legacy systems are still crucial as they support core business processes that cannot simply be replaced.

Pooyan Jamshidi is with IC4, School of Computing, Dublin City University, Dublin,Ireland (e-mail:ppooyan.jamshidi@.computing.dcu.ie).

Aakash Ahmad is with Lero, School of Computing, Dublin City University, Dublin, Ireland (e-mail: ahmad.aakash@,computing.dcu.ie).

Claus Pahl is with IC4, School of Computing, Dublin City University, Dublin, Ireland (e-mail: claus.pahl@computing.dcu.ie).
Some software-intensive applications cannot easily utilize cloud-based environments such as safety-critical software [3]. Some other applications such as embedded systems cannot necessarily benefit from this type of environment. Some software applications are specifically developed to operate in the cloud (cloud-native [3] or cloud optimized [7]). Some other systems are cloud-enabled [3] (cloud compatible, cloud ready or cloud aligned [7]) and must be adapted for the cloud. Our work is concerned with the migration effort of moving legacy on-premise software to target cloud environments.

Motivated by the promised benefits of cloud environments, there has been significant research on cloud-enabled software and facilitating the migration of legacy on-premise software to the cloud [3]. These approaches particularly focus on existing methods, techniques, processes and frameworks directly enabling migration or indirectly contributing towards justifying the decision of migrating to the cloud. The assumption for each of the approaches is that in its initial state, the software application is hosted on-premise in a non-cloud environment, e.g., on a local server, before the migration is applied to it. Therefore, migration between cloud providers, deployment models and virtual resources known as live migration is outside the scope of this work.

To-date, there has not been a systematic literature review (SLR) of research on cloud migration, making it difficult to assess the maturity in general and identifying trends, research gaps, and future dimensions of cloud migration in particular. Moreover, considering the growing demand for migration towards cloud, we need to investigate a research agenda for cloud migration. A SLR identifies, classifies and synthesizes a comparative overview of state-of-the-research and enables knowledge transfer in the research community [8] [9].

We conducted a SLR with the primary objective to identify, taxonomically classify, and systematically compare the existing research focused on planning, executing, and validating migration of legacy systems towards cloud-based software. More specifically, we aim to answers the following questions by conducting a methodological review of existing research: 
- What are the main practical motivations behind legacy migrations to the cloud?

- What are the existing tasks, methods and techniques to enable migration of legacy on-premise software to the cloud? In addition, what is the available tool support?

- What are the existing research themes? And what should form future research dimensions in legacy-to-cloud migration?

We followed guidelines in [8] [10]. Our objective is to systematically identify and taxonomically classify available evidence on cloud migration and provide a holistic comparison to analyze potential and limitations of existing research. This provides a systematic overview of current research, focusing on proposed methods, techniques and solutions in legacy-to-cloud migration. To this end, 23 studies are selected, classified and compared using a characterization framework. The characterization framework comprises of 12 analysis dimensions in terms of quantitative data items. These dimensions are derived and refined following a qualitative assessment of included studies and a validation of the review protocol [11], some well-known references [12] [1] [3] [5], and our experience with previous SLRs [13] [14].

The research synthesis resulted in a knowledge base [11] of current research approaches, methods, techniques, best practices and experiences used in legacy-to-cloud migration. This review reveals that cloud migration research is still in a formative stage, but based on evidence gathered, the maturity level is improving. This review identified the need for a standardized migration framework. The lack of attention to crosscutting concerns and migration execution is also observed. This study also showed a lack of tool support to automate and facilitate cloud migration tasks. The collected data in [11] - as an online literature base - provides a detailed insight and objective interpretation of the results. In particular, the results of this SLR are beneficial for

- Researchers in software engineering and cloud computing, who need an identification of relevant studies. A systematic presentation of research provides a body of knowledge to develop theory and solutions, analyze research implications and establish future dimensions.

- Practitioners interested in understanding the available methods and techniques with tool support as well as their constraints and maturity level in supporting legacy onpremise software migration to cloud-based environments.

The remainder of this paper is structured as follows. Section II describes background and related research to position contributions of this work. Section III explains our research methodology, research questions and scope. Section IV provides a reference model for state-of-the-research and a characterization scheme for cloud migration. Section V presents the results of the systematic review. Section VI discusses the main findings, implications and trends followed by an analysis of its limitations in Section VII. Finally, Section VIII concludes the paper.

\section{BACKGROUND AND RELATED WORK}

In this section, we explore the similarities and differences of SOA and cloud migration to justify why we position our contribution in the SOA migration context (Section II.A). We then define and position software migration in the context of software maintenance and evolution (Section II.B). Based on a systematic search (Section II.D), we link to existing secondary studies for migrating legacy software to SOA (Section II.C).

\section{A. SOA vs. Cloud migration: similarities and differences}

While service-oriented architecture (SOA) is yet to mature, cloud computing as a new computing paradigm emerges. In this section, we provide a generalization of terminologies for the two paradigms in order to objectively compare them. A comparison in three different themes is summarized in TABLE 1 .

\begin{tabular}{|c|c|c|}
\hline Perspectives & SOA migration & Cloud migration \\
\hline \multirow{3}{*}{ Drivers } & $\begin{array}{l}\text { Ease of software application integration for } \\
\text { inter-organization usage }\end{array}$ & Ease of infrastructure provisioning \\
\hline & Cost reduction through service reuse & $\begin{array}{l}\text { Cost saving for not owning infrastructure } \\
\text { and avoiding over-provisioning }\end{array}$ \\
\hline & Business agility in service-oriented processes & Elasticity to fluctuation of service requests \\
\hline \multirow{4}{*}{ Provisioning } & $\begin{array}{l}\text { Starts usually by one initial project with the } \\
\text { intention of being used by the others. }\end{array}$ & $\begin{array}{l}\text { Starts to meet specific project or program } \\
\text { needs. }\end{array}$ \\
\hline & $\begin{array}{l}\text { Services may be built through } \\
\text { component/service composition. }\end{array}$ & $\begin{array}{l}\text { Software/Platform/Infrastructure may be } \\
\text { created and administered through services. }\end{array}$ \\
\hline & $\begin{array}{l}\text { Governance is required throughout service } \\
\text { lifecycle. }\end{array}$ & $\begin{array}{l}\text { Governance is needed for employing cloud } \\
\text { services. }\end{array}$ \\
\hline & $\begin{array}{l}\text { Services are deployed on cloud-based } \\
\text { environment. }\end{array}$ & $\begin{array}{l}\text { Cloud uses shared pool of infrastructure } \\
\text { resources. }\end{array}$ \\
\hline \multirow{5}{*}{$\begin{array}{c}\text { Design } \\
\text { Principles }\end{array}$} & $\begin{array}{l}\text { Service-oriented architecture is used to } \\
\text { expose services within organizations or } \\
\text { between their business partners. }\end{array}$ & $\begin{array}{l}\text { Cloud services are used to expose services } \\
\text { mainly for customers. }\end{array}$ \\
\hline & The key design principle is loose coupling. & $\begin{array}{l}\text { The key principle is transparency in } \\
\text { computing utilities. }\end{array}$ \\
\hline & $\begin{array}{l}\text { Encapsulation and isolation from underlying } \\
\text { technologies is important. }\end{array}$ & $\begin{array}{l}\text { Encapsulation and isolation from } \\
\text { computing technologies is critical. }\end{array}$ \\
\hline & Promotes service reuse & Promotes flexible service delivery \\
\hline & $\begin{array}{l}\text { Multiple instances of a service serve a client } \\
\text { (multi-instance). }\end{array}$ & $\begin{array}{l}\text { Single instance of a software serves } \\
\text { multiple clients (multi-tenant). }\end{array}$ \\
\hline \multirow{3}{*}{$\begin{array}{l}\text { Crosscutting } \\
\text { Concerns }\end{array}$} & Security is overlooked. & Security is overstated. \\
\hline & $\begin{array}{l}\text { Requires participation of business and IT } \\
\text { stakeholders }\end{array}$ & Requires participation of IT stakeholders \\
\hline & Service is stereotyped as Web-service. & Cloud is stereotyped as computing units. \\
\hline
\end{tabular}

Drivers. Cost reduction and business agility are common drivers [15] [16]. Cost saving is a long-term driver for SOA as cost savings occur only when reuse of services reaches levels where the cost of creating the service is balanced. However, cost savings are immediate when a cloud environment is leveraged. Rationalization is also a common need of SOA and cloud computing. Business functionality in the case of SOA and infrastructure in the case of cloud are different targets.

Provisioning. Services often are created to meet tactical requirements and gain momentum in organizations as reuse grows. Service governance is essential to provide sustenance to enterprise services [15]. However, it is easier to procure and consume cloud services because their governance challenges are mostly limited to version compatibility [17] and data [18].

Design principles. In order to regulate how to create, organize and reuse software components, organizations often apply SOA and cloud computing as an architectural style [19] [2]. These enable business opportunities or technical benefits.

Crosscutting concerns. Security is often overlooked when deploying SOA services and overstated when using the cloud [16]. In cloud migration, active participation of technical staff are only required as opposed to SOA migration, which require involvement of business stakeholders as well. 


\section{B. Software migration and modernization}

According to the ISO/IEC standard for software maintenance and evolution [20], adaptive maintenance is defined as "modification of a software product performed after delivery to keep a software product usable in a changed or changing environment." We consider software migration as a special case of adaptive maintenance that deals with modification for a new environment. Software migration (or legacy modernization or software modernization) is a process of moving or adapting an existing system from one operating environment to another [20]. For example, moving from traditional ClientServer to SOA would usually be considered a migration because it involves making sure that new features are exploited, old settings do not require changes and ensures that applications continue to work in a new environment. Migration can be smallscale, e.g., migrating a single system, or large-scale, involving many systems, new applications or a redesigned system [21]. When functional equivalence has been reached between the initial and the transformed system, the migrated systems can be aligned more closely to current and future business needs through adding new functionality [6] [22].

\section{Secondary studies on legacy to SOA migration}

In recent years, secondary studies have focused on migration to SOA before cloud computing emerged. We did not find any secondary study on cloud migration (see Section D). On the other hand, according to the discussion in Section A, SOA and cloud migration are related. Thus, we decided to review existing secondary studies on SOA migration to position this SLR. We summarize these studies in TABLE 2 as secondary studies based on SLR [6], survey [23], research agenda [15] for future directions, survey in industry [21] [24], as well as reference framework [25] [22] addressing migration to SOA.

Systematic review on SOA migration. Khadka et al. [6] systematically reviewed 121 primary studies on legacy-to-SOA evolution using a software re-engineering reference framework. They provide a historic overview, focusing on methods and techniques used in a legacy-to-SOA evolution. They conducted a SLR to collect evolution approaches reported from 2000 to 2011. The resulting review constitutes the current research approaches, methods and techniques used and an identification of research directions for future research.

Research agenda for SOA migration. The Software Engineering Institute (SEI) has developed a SOA Research Agenda [15] within which the migration of legacy applications to SOA is also reviewed. The core is a taxonomy that classifies topics into the business, engineering and operations aspects of service-oriented systems, along with crosscutting aspects. Based on this taxonomy, the agenda outlines research areas, each identified with its rationale, overview of current research, and delineation of research challenges and gaps. It also provides details on specific research challenges related to the maintenance and evolution of service-oriented systems.

Survey on SOA/Cloud migration. Razavian and Lago [21] pinpoint a potential gap between theory and practice of legacyto-SOA migration. They conducted a systematic survey in industry. They synthesized the results based on their own reference migration framework [25] [22], contrasted with existing academic research. They discussed the differences and identified future research directions. In contrast to the previous industry-based survey, Almonaies et al. [23] survey approaches that deal with moving legacy software to SOA. They compare approaches and highlight strengths and weaknesses, thus providing a model for assisting decision support for migration projects. Pahl et al. [24] observed three different case studies in industry to identify the common migration processes and patterns based on expert interviews. Their work determines common principles that rule cloud migration processes, but also differences between the cloud deployment models. They proposed a process framework for different roles comprising SaaS/PaaS/IaaS (Software/Platform/Infrastructure as a Service) providers. This framework also lacks an explicit inclusion of post-migration activities and crosscutting concerns.

TABLE 2. A SUMMARY OF SECONDARY STUDIES ON SOA/CLOUD MIGRATION
\begin{tabular}{|c|l|l|l|l|c|}
\hline $\begin{array}{c}\text { Study } \\
\text { Type }\end{array}$ & \multicolumn{1}{|c|}{$\begin{array}{c}\text { Study } \\
\text { Reference }\end{array}$} & $\begin{array}{c}\text { Study } \\
\text { Focus }\end{array}$ & $\begin{array}{c}\text { Year of } \\
\text { Publication }\end{array}$ & $\begin{array}{c}\text { Total } \\
\text { Reviewed }\end{array}$ & $\begin{array}{c}\text { Covered } \\
\text { Years }\end{array}$ \\
\hline \multirow{2}{*}{ SLRs } & Khadka et al. [6] & $\begin{array}{l}\text { SOA } \\
\text { migration }\end{array}$ & 2013 & 121 & $2000-11$ \\
\cline { 2 - 7 } & Jamshidi et al. [11] & $\begin{array}{l}\text { Cloud } \\
\text { migration }\end{array}$ & 2013 & 23 & $2010-13$ \\
\hline \multirow{2}{*}{ Surveys } & Razavian et al. [21] & $\begin{array}{l}\text { SOA } \\
\text { migration }\end{array}$ & 2011 & 7 & -- \\
\cline { 2 - 7 } & Pahl et al. [24] & $\begin{array}{l}\text { Cloud } \\
\text { migration }\end{array}$ & 2013 & 3 & - \\
\cline { 2 - 7 } & Almonaies et al. [23] & $\begin{array}{l}\text { SOA } \\
\text { migration }\end{array}$ & 2010 & 21 & $2000-09$ \\
\hline $\begin{array}{c}\text { Research } \\
\text { Agenda }\end{array}$ & SEI [15] & SOA & 2010 & -- & - \\
\hline
\end{tabular}

Concluding remark. In terms of the research methodology, the work of Khadka et al. [6] is the closest work to ours; however, we focus on migration to the cloud. In terms of a conceptual framework for characterization of migration approaches, the work of Razavian and Lago [22] is the closest work to ours. Nonetheless, according to the discussion Section D, we believe that our work is the first attempt to consolidate cloud migration studies.

\section{The needs for a secondary study on cloud migration}

The need for a SLR entails to identify, classify and compare existing evidence on the migration of legacy software systems to cloud environments through a characterization framework. It exclusively focuses on classification and comparison of cloud migration approaches. In order to demonstrate that a similar review has not been already reported, we searched the Compendex, IEEE Xplore, ACM and Google Scholar digital libraries (on 1/4/2013) with the following search string:

$$
\text { Cloud [AND] }
$$

Migration $<\mathrm{OR}>$ Evolution $<\mathrm{OR}>$ Adaptation $<\mathrm{OR}>$ Transformation $<\mathrm{OR}>$ Modernization $<\mathrm{OR}>$ Reengineering $<\mathrm{OR}>$ Integration $<\mathrm{OR}>$ Adoption [AND]

Systematic Literature Review $<\mathrm{OR}>$ Systematic Review $<\mathrm{OR}>$ SLR $<\mathrm{OR}>$ Systematic Mapping $<\mathrm{OR}>$ Literature Survey $<\mathrm{OR}>$ Research Review $<\mathrm{OR}>$ Research Synthesis $<O R>$ Research Synthesis $<\mathrm{OR}>$ Secondary Study

None of the retrieved secondary studies was related to any of our research questions detailed in Section III. Considering the importance of cloud migration and the relative maturity of this field (see Section VI.A), a consolidation of existing evidence on legacy-to-cloud migration is timely. 


\section{ReSEARCH Methodology}

In contrast to a non-structured review process, a systematic literature review [8] reduces bias and follows a precise and rigorous sequence of methodological steps to research literature. SLRs rely on well-defined and evaluated review protocols to extract, analyze and document results as illustrated in FIGURE 1. We adopted the guidelines in [8] with a three-step review process that includes planning, conducting and documenting. The review is complemented by an external evaluation of the outcome of each step. We also provide an explicit characterization framework of the reviewed studies. This is the foundation for a comparative analysis of studies based on our analysis dimensions (see Section IV). These analysis dimensions are also subject to external evaluation.

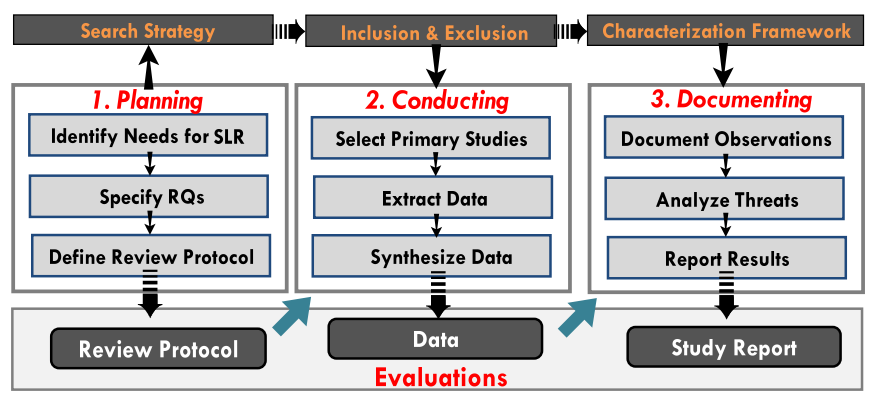

FIGURE 1. OVERVIEW OF OUR RESEARCH METHODOLOGY

We now summarize the planning and conducting phases of the methodology that we followed for performing this SLR, see FIGURE 1 . The results are documented in terms of a data summary in Section V and in terms of findings and research implications in Section VI. Data is collected and synthesized by adopting a framework, which is proposed in Section IV.

\section{A. Planning the Review}

Planning starts with an identification of the needs for a systematic review and results in a review protocol as follows:

\begin{tabular}{|c|c|}
\hline Research Question & Motivation \\
\hline $\begin{array}{l}\text { RQ1 - What are the main practical motivations } \\
\text { behind legacy migrations towards the cloud? }\end{array}$ & $\begin{array}{l}\text { The aim is to get insight in what are the main } \\
\text { reasons for organizations to migrate their legacy } \\
\text { application to cloud-based environments. }\end{array}$ \\
\hline $\begin{array}{l}\text { RQ2 - What are the different type of migration and } \\
\text { main migration tasks involved? }\end{array}$ & $\begin{array}{l}\text { The aim is to investigate what are the possibilities } \\
\text { for cloud enabling on-premise software and the } \\
\text { involved tasks for a migration towards cloud. }\end{array}$ \\
\hline $\begin{array}{l}\text { RQ3 - What are the existing methods, techniques } \\
\text { and tool support to enable migration of legacy } \\
\text { software towards cloud-based environment? }\end{array}$ & $\begin{array}{l}\text { The aim is to identify and compare existing } \\
\text { methods and techniques that support cloud } \\
\text { migration. }\end{array}$ \\
\hline $\begin{array}{l}\text { RQ4 - What are the existing research issues and } \\
\text { what should be the future research agenda in legacy } \\
\text { to cloud migration? }\end{array}$ & $\begin{array}{l}\text { The aim is to understand and reveal the research } \\
\text { gaps need to be addressed and potential future } \\
\text { directions in this field. }\end{array}$ \\
\hline
\end{tabular}

Step 1 -Identify the need for SLR. The need is identified and the contribution of this SLR justified in Section II. In addition, we specify the research questions in TABLE 3 that help in defining and evaluating the review protocol to conduct the SLR. We also formulated the general goal and scope of the study through PICOC (Population, Intervention, Comparison, Outcome and Context) criteria [9] in TABLE 4.

Step 2 - Specifying the Research Questions. The research questions are based on our motivation, i.e., answers provide us an evidence-based overview of migration approaches. We define four research questions that represent the foundation for deriving the search strategy for literature extraction, see TABLE
3. The motivation outlines the primary objective of investigation for each question. In addition, a comparative analysis allows us to analyze the collective impact of research, represented in terms of comparison attributes (Section IV).

\begin{tabular}{|l|l|l|l|c|}
\multicolumn{1}{|c|}{ TABLE 4. PICOC CRITERIA TO DEFINE SCOPE AND GOALS OF THE SLR } \\
\hline Criteria & \multicolumn{1}{c|}{ RQ1 } & \multicolumn{1}{c|}{ RQ2 } & \multicolumn{1}{c|}{ RQ3 } & \multicolumn{1}{c|}{ RQ4 } \\
\hline Population & $\begin{array}{l}\text { Practical } \\
\text { motivation }\end{array}$ & $\begin{array}{l}\text { Migration } \\
\text { tasks }\end{array}$ & $\begin{array}{l}\text { Methods and } \\
\text { techniques }\end{array}$ & $\begin{array}{l}\text { Research challenges } \\
\text { and future dimensions }\end{array}$ \\
\hline Intervention & $\begin{array}{l}\text { Characterization, Internal/external validation; Extracting data and } \\
\text { Synthesis }\end{array}$ \\
\hline Comparison & $\begin{array}{l}\text { A comparison by mapping the primary studies to a characterization } \\
\text { framework }\end{array}$ \\
\hline Outcome & $\begin{array}{l}\text { A characterization framework; Classification and comparison; } \\
\text { Hypotheses for future research }\end{array}$ \\
\hline Context & $\begin{array}{l}\text { A systematic investigation to consolidate the peer-reviewed } \\
\text { research }\end{array}$ \\
\hline
\end{tabular}

Step 3 - Define and Evaluate Review Protocol. Based on the objectives, we specify the research questions and the review scope in order to formulate search strings for literature extraction. We also developed a protocol for a systematic review by following [8] and our experience with SLRs [13] [14]. As suggested by [8] and [13], we externally evaluated the protocol before its execution. We asked an external expert for feedback, who had experience in conducting SLRs in an area overlapping with cloud computing. His feedback is reflected in a refined protocol. We also performed a pilot study of the systematic review with five (approximately 25\%) of the included studies. The objective for conducting a pilot study was to first reduce the bias between the researchers and iteratively improve the characterization scheme for data collection. We expanded the review scope, improved search strategies and refined the inclusion/exclusion criteria during the pilot studies (see Section B for details).

\section{B. Conducting the Review}

Conducting is the second phase starting with study selection and results in extracted data and synthesized information:

Step 1 - Select primary studies. The search terms used were developed using [8] and guided by research questions (TABLE 3). This resulted in a composition of 675 distinct search strings applied to six databases, see FiguRE 2 . We extracted 1351 peerreviewed literature from years 2005 to 2013 (inclusive). The year 2005 was chosen as preliminary search found no earlier results related to the research questions. Since we used our primary search criteria on title and abstract, this resulted in a high number of irrelevant studies, which were further refined with a secondary search.

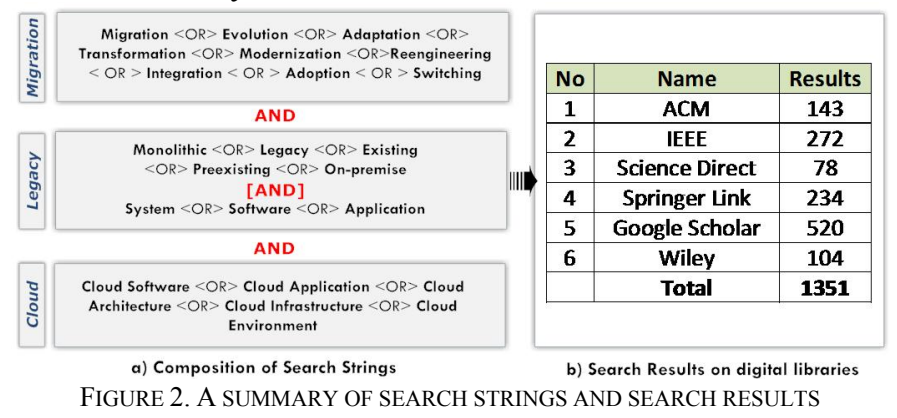

Study Selection and Qualitative Assessment. The selection phase comprises of three steps, see FIgURE 3 , initial search in 
databases, inclusion/exclusion and final selection based on quality assessment.

- Initial Selection: This process includes screening of titles and abstracts of potential primary studies - performed by the researchers against inclusion/exclusion criteria in Table 5. For almost $20 \%$ (4) of studies, no decision could be made. In such cases, exclusion or proceeding to final selection involved examining the full text.

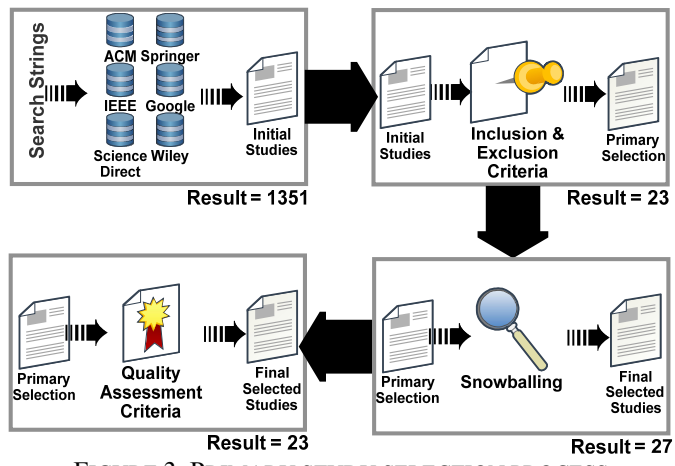

FIGURE 3. PRIMARY STUDY SELECTION PROCESS

- Final Selection: This is based on a validation scan of the studies, means of migration and tool support and details of the evaluation approach. After performing this step, 23 studies were selected. During the secondary search process, references and citations for the 23 studies were reviewed. Guidelines [10] recommend that snowballing from reference lists of the identified articles should be used in addition to searches in databases in order to identify additional relevant articles through the reference lists of the articles found using search strings. This technique led to the inclusion of more four relevant studies. As a result, 27 studies were included for qualitative assessment.

- Qualitative Assessment of Included Studies: For the 27 included studies, we primarily focused on the technical rigor of content presented. We based our qualitative assessment on factors like General Assessment (G) and Specific Assessment (S), summarized in TABLE 6. Additional details about the quality checklist are provided in [11]. Quality scores provided us with a numerical quantification to rank the selected studies. Since all of the identified studies have been published in very recent years, we did not rank them based on number of citations.

TABLE 5. INCLUSION AND EXCLUSION CRITERIA

\begin{tabular}{|c|c|c|}
\hline \multirow{3}{*}{ 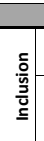 } & Criteria & Rationale \\
\hline & $\begin{array}{l}\text { 11: studies in the form of a scientific } \\
\text { peer-reviewed paper. }\end{array}$ & $\begin{array}{l}\text { A scientific paper guarantees a certain level of quality through } \\
\text { a peer review and contains a substantial amount of content. }\end{array}$ \\
\hline & $\begin{array}{l}\text { 12: Studies that propose solution, } \\
\text { experience, or evaluation of cloud } \\
\text { migration. }\end{array}$ & $\begin{array}{l}\text { We are interested in specific solutions, metrics, and analyses of } \\
\text { legacy to cloud modernization. }\end{array}$ \\
\hline \multirow{7}{*}{ 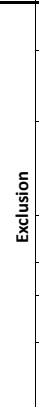 } & $\begin{array}{l}\text { E1: Studies that do not explicitly discuss } \\
\text { legacy to cloud migration. }\end{array}$ & $\begin{array}{l}\text { Our objective is to study cloud migration, so we exclude any } \\
\text { other legacy modernization, e.g. legacy to SOA. }\end{array}$ \\
\hline & $\begin{array}{l}\text { E2: Studies that investigate migration } \\
\text { between cloud providers. }\end{array}$ & $\begin{array}{l}\text { These studies are not associated with legacy to cloud } \\
\text { migration. Instead, they explore the migration between cloud } \\
\text { providers and deployment models also known as live migration. }\end{array}$ \\
\hline & $\begin{array}{l}\text { E3: Studies that do not explicitly propose } \\
\text { a method, technique or tool to facilitate } \\
\text { a migration task. }\end{array}$ & $\begin{array}{l}\text { These studies are not directly enabling migration or even } \\
\text { decision making rather they influence for example the } \\
\text { decisions for migration. For example, studies which are related } \\
\text { to migration enablers and inhibitors. }\end{array}$ \\
\hline & $\begin{array}{l}\text { E4: Editorials, abstracts or short papers } \\
\text { (shorter than } 6 \text { pages) }\end{array}$ & $\begin{array}{l}\text { These studies do not provide a reasonable amount of } \\
\text { information for an objective decision. }\end{array}$ \\
\hline & E5: Secondary studies & These studies do not propose any specific solution. \\
\hline & $\begin{array}{l}\text { E6: Non-peer-reviewed studies, white } \\
\text { papers, or non-English manuscripts }\end{array}$ & $\begin{array}{l}\text { Although there are numerous white papers in cloud migration } \\
\text { but we decided to exclude them because they are situational. }\end{array}$ \\
\hline & E7: Thesis and book chapters & $\begin{array}{l}\text { These studies usually are associated with conference or journal } \\
\text { papers and for the entire retrieved thesis or book chapters, we } \\
\text { included the most related paper of the corresponding author. }\end{array}$ \\
\hline
\end{tabular}

Based on the quality assessment checklist in Table 6, we defined a quality ranking formula. $G$ represents five factors as general assessment criteria from TABLE 6, providing a maximum score of one ( $25 \%$ weight). S represents five factors as specific items provide a maximum score of three. $\mathrm{S}$ is weighted three times more than $\mathrm{G}$ ( $75 \%$ weight) as specific contributions of a study are more important than general factors for assessment. Based on consensus among the researchers and suggestions from external reviewers, the criteria for qualitative assessment maximum score was $\mathrm{G}+\mathrm{S}=4$ where a 3-4 score represented quality papers, a score less than 3 and greater than or equal to 1.5 is acceptable and a score less than 1.5 results in exclusion.

$$
\text { Quality Score }=\left[\frac{\sum_{i=1}^{5} G_{i}}{5}+\left(\frac{\sum_{i=1}^{5} S_{i}}{5} \times 3\right)\right]
$$

Based on the qualitative assessment of 27 studies, we selected 23 studies, listed with bibliography, quality score and citation count in TABLE 14 . Note that quality ranking is an internal metric only that helps us to choose most related studies and does not reflect any comparison or objective interpretation of selected studies.

Steps 2 and 3 - Data Extraction and Synthesis. In order to record the extracted data from the selected studies, we followed [8] and designed a structured format based on characterization dimensions as explained in Section IV. A structured comparative analysis enables an investigation of the collective impact of research by analyzing the potential and limitation of existing research and possible reflections on future trends. Additional details can be found in [11].

TABLE 6. QUALITY ASSESSMENT CHECKLIST

\begin{tabular}{|c|c|c|c|c|}
\hline \multirow{2}{*}{\multicolumn{2}{|c|}{ General Items for Quality Assessment (G) }} & \multicolumn{3}{|c|}{ Score } \\
\hline & & \multirow[t]{2}{*}{\begin{tabular}{l|}
$\begin{array}{l}\text { Yes } \\
=1\end{array}$ \\
\end{tabular}} & \multirow[t]{2}{*}{$\begin{array}{c}\begin{array}{c}\text { Partially } \\
=0.5\end{array} \\
\end{array}$} & \multirow[t]{2}{*}{$\begin{array}{c}\mathrm{No}= \\
0\end{array}$} \\
\hline G1 & Are problem definition and motivation of the study clearly presented? & & & \\
\hline G2 & Is the research environment in which the study was carried out explained? & & & \\
\hline G3 & Are research methodology and its organization clearly stated? & & & \\
\hline G4 & Are the contributions of the study inline with presented results? & & & \\
\hline G5 & Are the insights and lessons learnt from the study explicitly mentioned? & & & \\
\hline \multicolumn{2}{|r|}{ Specific Items for Quality Assessment (S) } & & & \\
\hline S1 & Is the research clearly focused on migration towards cloud? & & & \\
\hline $\mathbf{S 2}$ & Are the details about related research clearly addressing migration support? & & & \\
\hline $\mathbf{S 3}$ & Is the research evaluation clearly illustrates cloud migration support? & & & \\
\hline $\mathbf{S 4}$ & Are the results clearly validated in a non-trivial evaluation context? & & & \\
\hline S5 & Are limitations and future implications for cloud migration clearly positioned? & & & \\
\hline
\end{tabular}

\section{A FrAMEWORK FOR ClASSIFICATION AND COMPARISON of Cloud Migration RESEARCH}

In this section, we first introduce a cloud migration reference model for a process-centric classification of cloud migration that can help to demonstrate current research at a conceptual level and identify trends and research directions. The details of this model are discussed in Section IV.A. We then present a framework in Section IV.B to characterize individual cloud migration approaches that helps us to taxonomically classify and compare the primary studies.

\section{A. Cloud-RMM: a cloud migration reference model}

As discussed in II.A, SOA and cloud migration are not entirely distinct, but complementary areas (cf. TABLE 1). By investigating the established reference models and frameworks [25] [6] [26] for SOA migration as well as the commonalities in the primary studies, we derive a reference model as a 
conceptual framework to represent different process areas in cloud migration studies. The aim of this reference model is to identify areas that existing work is concentrated on and areas not covered. By identifying these areas, we can identify trends and directions of research on cloud migration.

\section{1) Existing SOA migration frameworks}

SOA-MF. Razavian and Lago [25] proposed a comprehensive SOA Migration Framework, called SOA-MF, which follows the horseshoe model for software reengineering [27]. The framework involves three processes: (i) reverse engineering, (ii) transformation and (iii) forward engineering. The basis for SOA-MF is to first recover lost abstractions and then to elicit legacy fragments that are ready for migration to SOA. Secondly, it remodels the legacy abstractions to servicebased abstractions, and finally, renovating the target system based on transformed abstractions and new requirements. The same authors in another study [22] identified migration categories based on a mapping of evidence to SOA-MF.

SOA Evaluation framework. Khadka [6] developed a migration framework for legacy-to-SOA evolution. They identify common methods in four different reengineering frameworks using method engineering [19]. This framework consists of six phases in two generic stages. In the first, migration is planned; in the second, it is performed. However, they do not consider migration validation, an important step after performing and implementing migration. In addition, they do not consider crosscutting activities such as governance.

SMART. The SEI [26] has developed a SOA migration framework that helps organizations to analyze legacy systems and migrate them to a service-based system. SMART consists of five processes. This framework has shortcomings [25]. They only concentrate on early stages and do not cover forward engineering activities. Transformation is only performed at conceptual level rather than on software.

\section{2) Cloud-RMM reference model}

We now introduce a conceptual model called Cloud-RMM (Cloud - Reference Migration Model), which represents a reference model to classify research in terms of distinct processes and crosscutting concerns. In order to develop a reference model for legacy-to-cloud, we first need to adopt a method to formally represent the conceptual model. Based on previous experience [19], we adopt situational method engineering [28] to consolidate existing frameworks in cloud migration (e.g., CloudMIG [S20], CMotion [S8], CloudGenius [S4], CloudStep [S5], Cloud Adoption Toolkit [S21], Cloudward Bound [S22]). Note that the notation [Sn] ( $n$ is a number) represents a reference to studies included in the SLR, listed in TABLE 14 . We identify the key processes related to cloud migration. In method engineering, one can follow a bottom-up approach by identifying low-level activities and techniques and then categorize them to form generalized tasks and processes. Alternatively, a top-down approach forms a framework consisting of processes, tasks, activities and techniques. We extracted a list of common migration tasks by exploring the defined migration tasks in the primary studies. Then, we identified categories of closely related tasks in terms of input or output artifacts as well as the involved activities to form key processes for migration. A detailed description of the process we followed to identify these method chunks can be found in [19]. FIGURE 4 represents the Cloud-RMM migration framework, which consists of 4 processes and 20 migration tasks. Any activities within the scope of porting a software system (or part of the system) from on-premise hosts such as local data centers to selected cloud platforms preserving the core functionalities are regarded as migration tasks.

Process I. Migration planning. In the first process, preliminary migration tasks such as feasibility study [S8] [S10] [S11] [S12] [S21], migration requirement analysis [S8] [S13] [S14] [S17], as well as some decision making regarding which provider to choose [S1] [S2] [S5] [S10] [S11] [S14] [S23], which subsystems to be migrated [S1] [S10] [S11] [S13] [S22], and which cloud services to use [S4] [S6] [S9] [S10] [S11] [S23], and migration strategy development [S8] [S5] [S7] [S10] [S19] are conducted. The output artifact is a migration plan.

Process II. Migration execution. In the second process, the actual migration tasks such as data extraction [S6] [S8] [S15] and architecture recovery [S2] [S6] [S8] [S15] [S17] [S19] and adaptation [S8] [S23] as well as code modification and wrapping [S13] [S16] [S19] and legacy-to-cloud transformation [S2] [S15] [S16] at both conceptual and concrete levels are executed.

Process III. Migration evaluation. In the third process, the migrated system is ready for use and validation. Tasks such as testing [S2] [S6] [S13] [S15] [S16] [S17], validation [S3] [S15] [S20] and deployment [S1] [S8] [S13] [S16] of migrated application are performed.

Process IV. Crosscutting concerns. Some crosscutting tasks such as governance [S8], security analysis [S8] [S17] [S22], training [S6] [S7] [S16], effort estimation [S18], organizational change [21] and multi-tenancy and elasticity analysis [S8] act as umbrella activities in the framework.

According to FIGURE 4, test, architecture recovery and decision of cloud providers are the most common migration tasks and crosscutting tasks as well as architecture adaptation are the least popular tasks among the primary studies. In terms of automated support, for processes I and III, there is satisfactory evidence, but for process II and crosscutting concerns, the evidence amount is unsatisfactory.

Implications of Cloud-RMM. This reference model helps to conceptualize a process-centric view for state-of-the-research and literature classification into processes and associated tasks. Cloud-RMM can distinguish solutions for migration.

\section{B. A characterization framework for cloud migration ${ }^{l}$}

In this section, we present a framework consisting of twelve data items to characterize approaches that enable legacy migration towards cloud-based environments - see TABLE 7. This framework constitutes a foundation for evaluating and comparing migration approaches. It can also be used as a means

\footnotetext{
${ }^{1}$ http://www.computing.dcu.ie/ pjamshidi/SLR/SLR-CM.html
} 
to taxonomically classify research on migration. For each of the data items, the framework considers a set of well-defined classification options. We derive these options by combining classification options from seminal sources [12] [1] [3] [5] [29] with those found in the set of papers that we selected, e.g., the set of options for the "contribution type" was identified based on the taxonomy proposed by [12].

In TABLE 7, we focus on the description of the analysis dimensions and their associated options. For each dimension listed, we either provide a definition for the item or define its options separately. Note that the twelve analysis dimensions are categorized in four different categories. These categories comprise of migration characterization, migration support, constraints on migration and maturity level. For a detailed description of the framework, refer to [11].

\section{RESULTS}

This section presents the results of SLR according to the protocol presented in Section III. We give an overview of the selected studies in Section I.A. We then present a taxonomical classification and comparison of the studies in Section VI.A by answering the primary research questions (cf. TABLE 3 ).

\section{A. Overview of the primary studies}

To examine the state of research on cloud migration, the following complementary questions are considered:

- When did research on cloud migration become active in computing community?
- What are the fora in which work on cloud migration has been published? In which communities do they focus?

- What are the active research communities and groups in cloud migration research?

- How cloud migration research is reported and what is the maturity level of the research in this field?

\section{1) Temporal overview of studies}

The number of studies by year of publication is shown in FIGURE 5. The earliest research results are published in 2010 and significantly increased in 2011 . Note that for 2013, the review only covers papers until May. For this reason, there is a decrease in the number of papers in 2013, which would in normal circumstances have been followed by more studies as the previous years. We also annotate the means of migration (third data item in TABLE 7) as well as maturity level (second data items in TABLE 7) of the published paper in each year in Figure 5. The work in cloud migration started with experiences with small case studies [S7] in 2010. This is complemented by a variety of contributions enabling migration (e.g., model transformation [S2]) and facilitating decision making (e.g., migration decision support [S3]). For the last two years with good evidence of cloud migration approaches, the trend continues with quite mature best practice and surveys [S8].

\section{2) Publication fora}

The selected papers are listed in TABLE 14. As indicated in TABLE 8, the majority of these studies have been published in two service and cloud computing conferences and two workshops, namely SERVICES, CLOUD, SECLOUD and MESOCA.

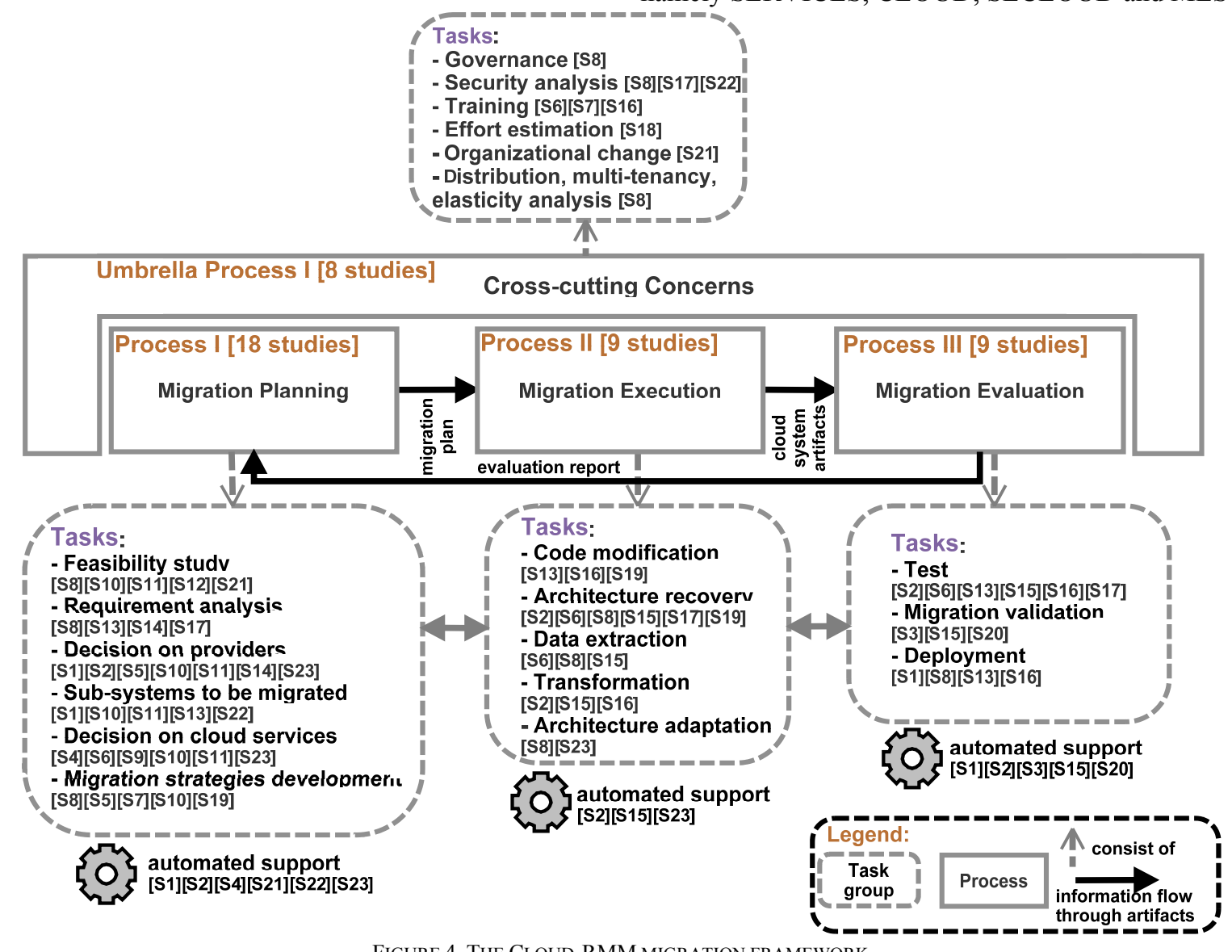

FIGURE 4. THE CLOUD-RMM MIGRATION FRAMEWORK 
TABLE 7. DATA ITEMS IN THE CHARACTERIZATION FRAMEWORK FOR MIGRATION OF LEGACY SOFTWARE TOWARDS CLOUD
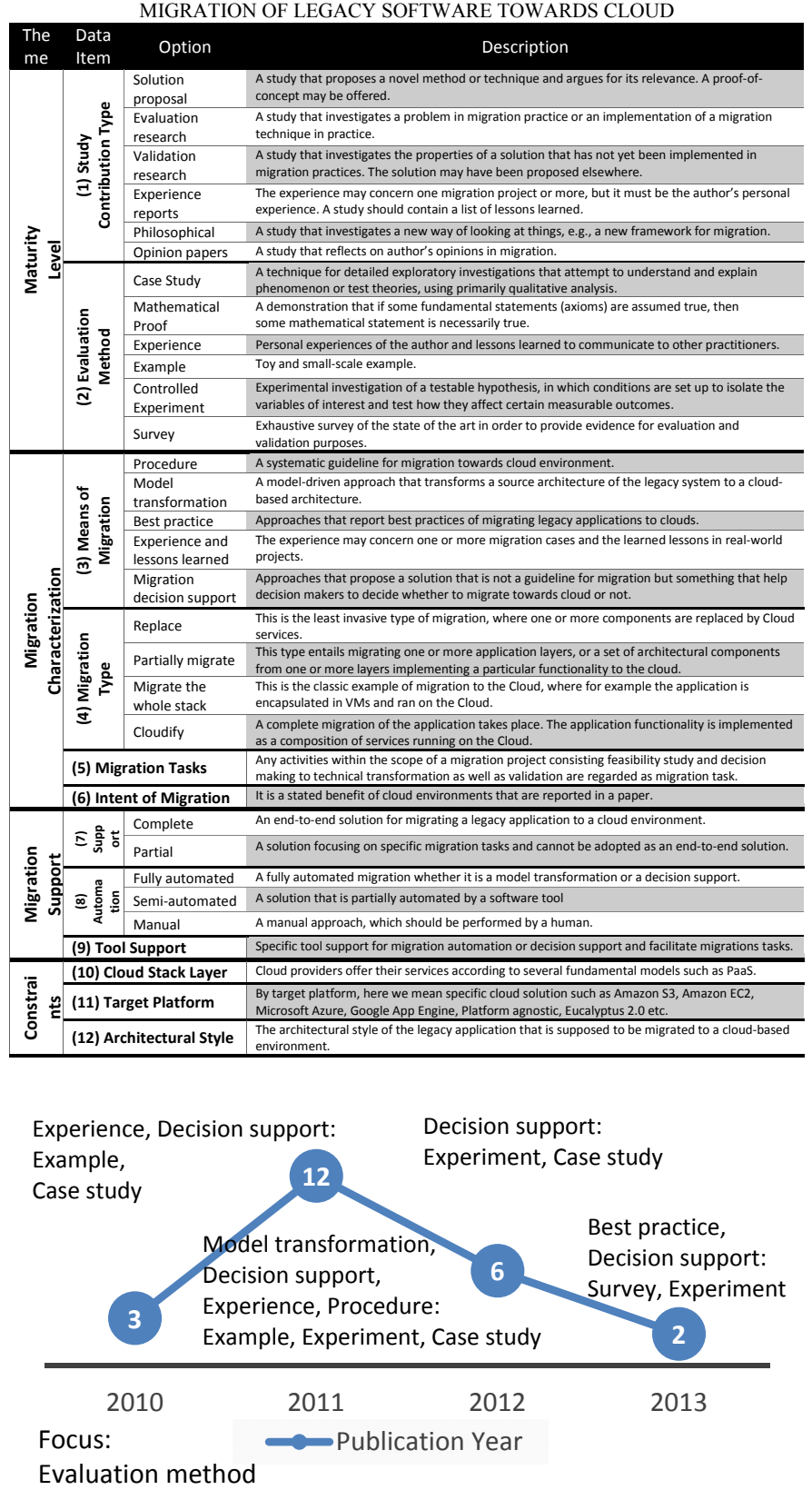

FIGURE 5. TEMPORAL DISTRIBUTION OF THE INCLUDED STUDIES

\begin{tabular}{|c|c|c|c|c|}
\hline Publication Channel & Abbreviation & Count & Category & Community \\
\hline EEE World Congress on Services & SERVICES & 3 & \multirow{4}{*}{$\begin{array}{l}\text { Leading } \\
\text { conferes } \\
\text { and } \\
\text { workshops }\end{array}$} & Service/Cloud \\
\hline International Conference on Cloud Computing & CLOUD & & & Service/lloud \\
\hline $\begin{array}{l}\text { ICSS International W } \\
\text { Cloud Computing }\end{array}$ & SELLOUD & 3 & & Software Engineering \\
\hline $\begin{array}{l}\text { ISSM International Workshop on the Maintenance and } \\
\text { Evvolution of Service-Oriented and Cloudd-Based SSystem }\end{array}$ & MESOCA & 2 & & Software Engineering \\
\hline Journal of Software Maintenance and Evolution: Research & ISEP & 1 & \multirow{4}{*}{$\begin{array}{l}\text { Major } \\
\text { journals }\end{array}$} & Software Engineering \\
\hline Softwaref: Practice and Experience & SPE & 1 & & Software Engineering \\
\hline International Journal on Advances in Software & & & & $\begin{array}{l}\text { Soltware bimeeris } \\
\text { Software }\end{array}$ \\
\hline Springer Computing & Computing & 1 & & Computing \\
\hline $\begin{array}{l}\text { International Conference on Software Engineering } \\
\text { ACC Sppecial Interest }\end{array}$ & ICSE & 1 & \multirow{7}{*}{$\begin{array}{c}\text { Major } \\
\text { conferences }\end{array}$} & $\begin{array}{l}\text { Software Engineering } \\
\text { Data Communication }\end{array}$ \\
\hline European Conference on Software Maintenance and & CSMR & 1 & & Software Engineering \\
\hline $\begin{array}{l}\text { Reengineering } \\
\text { International Conference on }\end{array}$ & $w w w$ & 1 & & \\
\hline Internati & 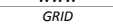 & 1 & & \\
\hline USENIX conference on Hot topics in cloud computing & Hotcloud & 1 & & Service//loud \\
\hline $\begin{array}{l}\text { International Conferencene on rust, Security and Pri } \\
\text { Computing and communicictions }\end{array}$ & Trustcom & 1 & & Security \\
\hline International Symposium on Empirical Software Engineering & ESEM & 1 & & Software Engineering \\
\hline
\end{tabular}

Among the 23 included studies, four of them are published in the following software engineering journals JSEP (impact factor: 0.844), SPE (impact factor: 0.519), IJAS and Computing (impact factor: 0.701). As indicated in Table 8, most of the papers are published in service-oriented, cloud computing and software engineering communities.

\section{3) Active research communities}

Another distribution considers active research communities. We looked at author affiliations (after the study selection and synthesis to eliminate affiliation-bias). Active communities that proposed at least two included studies are listed along with their research focus in TABLE 9. A considerable number of studies are associated with migration decision support are published by researchers in University of Kiel in Germany and University of New South Wales in Australia and I0042M Research in the US. While researchers at University of St Andrews in the UK, IT University of Copenhagen in Denmark and Mälardalen University in Sweden focus on experience and lessons learned.

TABLE 9. ACTIVE COMMUNITIES AND THEIR RESEARCH FOCUS

\begin{tabular}{|l|l|c|}
\hline Affiliation & Study ID & Research Focus \\
\hline $\begin{array}{l}\text { Software Engineering Group, University of Kiel, } \\
\text { Germany }\end{array}$ & {$[\mathrm{S} 1][\mathrm{S} 2][\mathrm{S} 3][\mathrm{S} 20][\mathrm{S} 23]$} & $\begin{array}{c}\text { Migration } \\
\text { decision support }\end{array}$ \\
\hline $\begin{array}{l}\text { School of Computer Science and Engineering, } \\
\text { University of New South Wales, Australia }\end{array}$ & {$[\mathrm{S} 4][\mathrm{S} 16]$} & $\begin{array}{c}\text { Migration } \\
\text { decision support }\end{array}$ \\
\hline $\begin{array}{l}\text { School of Computer Science, University of St } \\
\text { Andrews, UK }\end{array}$ & {$[\mathrm{S} 7][\mathrm{S} 21]$} & $\begin{array}{c}\text { Experience and } \\
\text { lessons learned }\end{array}$ \\
\hline $\begin{array}{l}\text { Software and Systems Section, IT University of } \\
\text { Copenhagen, Denmark }\end{array}$ & {$[\mathrm{S} 13][\mathrm{S} 17]$} & $\begin{array}{c}\text { Experience and } \\
\text { lessons learned }\end{array}$ \\
\hline $\begin{array}{l}\text { School of Innovation, Design, and Engineering, } \\
\text { Mälardalen University, Sweden }\end{array}$ & {$[\mathrm{S} 13][\mathrm{S} 17]$} & $\begin{array}{c}\text { Experience and } \\
\text { lessons learned }\end{array}$ \\
\hline IBM Research, US & {$[\mathrm{S} 15][\mathrm{S} 22]$} & $\begin{array}{c}\text { Migration } \\
\text { decision support }\end{array}$ \\
\hline
\end{tabular}

\section{4) Research methods for cloud migration}

Since the included studies are peer-reviewed, data about research methods (comprising contribution type and evaluation method) adopted has been extracted. A detailed analysis of research methods is outside the scope here.

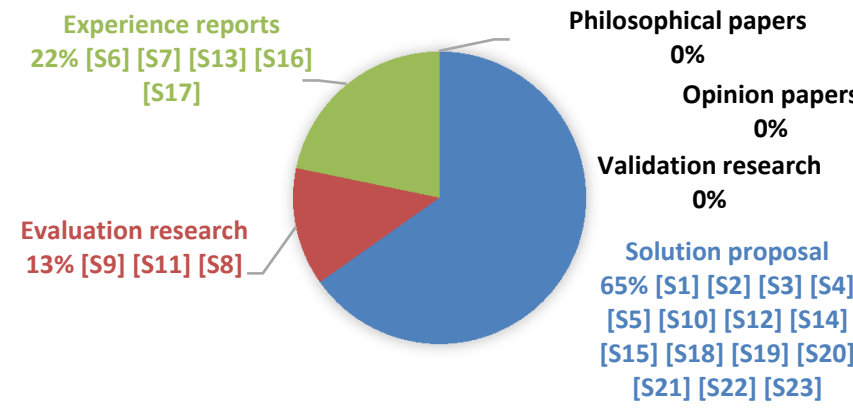

FIGURE 6. DISTRIBUTION OF STUDIES ACCORDING TO CONTRIBUTION TYPE

Contribution type. Based on the analysis of Figure 6, we can conclude that the largest set of contributions in the legacy-tocloud migration relates to solution proposals (65\%). Experience report and evaluation research are respectively associated to $22 \%$ and $13 \%$ of the studies. This indicates a lack of validation research, philosophical and opinion papers.

Evaluation method. FigurE 7 suggests that controlled experiments and case studies are the most common evaluation method adopted. Controlled experiments support quantitative analysis and scientific investigation of particular migration approaches, but ignore contextual factors and real situations. 
Case studies are good for real-world cases and effects. Additionally, $16 \%$ of the studies used toy examples to evaluate their contributions. As FIGURE 7 indicates, there is a clear lack of mathematical proofs, survey and experience reports and evaluation approaches in the selected studies.

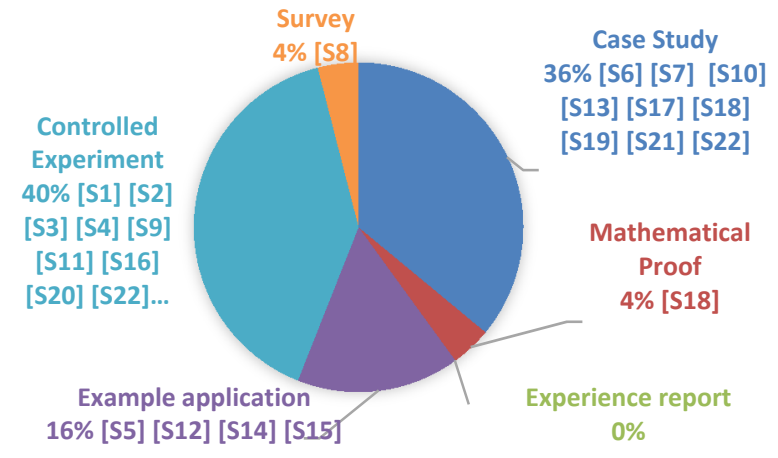

FigURE 7. DISTRIBUTION OF STUDIES ACCORDING TO EVALUATION METHOD

\section{A. A taxonomical classification and comparison of cloud migration methods and techniques}

The results of study syntheses are now summarized to answer the primary research questions. The characterization framework, introduced in Section IV, is used as a holistic framework for taxonomical classification and comparison.

\section{1) Primary drivers for cloud migration}

We answer RQ1 to identify primary motivations for cloud adoption. Based on data synthesis, we identified three primary factors that drive migration to the cloud, see FIGURE 8 :

- Operational cost saving ( $48 \%$ of the studies)

- Application scalability (26\% of the studies)

- Efficient utilization of resources (21\% of the studies)

Interestingly, cost saving is only indicated by $16 \%$ of participants in a UK-based industry survey as a key driver for cloud adoption [30]. This slightly grew in a 2012 version of the same survey, confirming that benefits are real, but are still secondary benefits from an industrial perspective. However, in the recent version in 2013, in a departure from previous research, cost saving for the first time becomes the primary reason for cloud adoption. A significant percentage (initially $53 \%$ and in the newer version $46 \%$ ) refer to flexibility as the reason that the cloud brings to the organization. In another survey performed by the same forum, but for industries based in the US, $28 \%$ of the participants voted for cost saving as opposed to $31 \%$ for flexibility [31]. Application scalability is reported as a third important driver for cloud adoption.

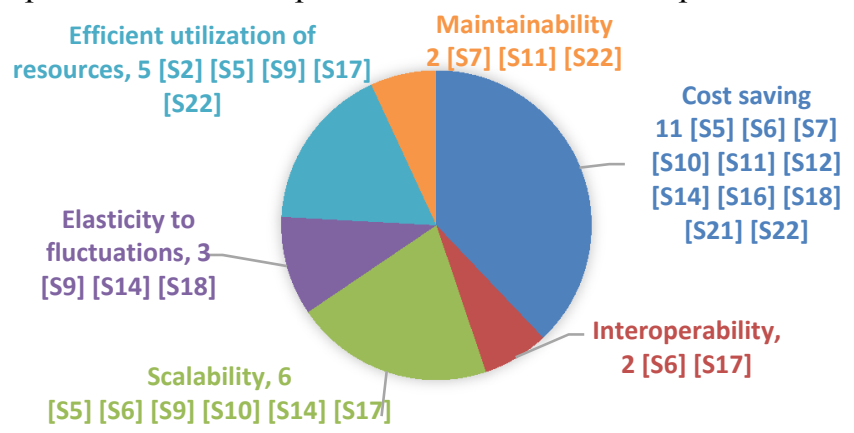

FIGURE 8. NUMBER OF STUDIES WITH RESPECT TO DRIVER OF MIGRATION
The findings clearly highlight that cost saving, scalability and efficient utilization of resources as well as flexibility are key drivers to migrate application to the cloud.

\section{2) Migration types}

We answer RQ2 by illustrating different migration types. The other part of this question regarding involved migration tasks is already answered through the Cloud-RMM framework in Section IV.A.2). In order to distinguish between different types of migration, we borrowed the classification proposed in [3], see FIGURE 9, considering different application layers and different degrees of adaptation required to enable migration.

Type I (replace) application tiers with cloud offerings is the least invasive migration type. Data and/or business tiers have to be migrated to the cloud stack. We could not identify any evidence of this type of migration in the selected studies (cf. FIGURE 9), partly because this type of migration is regarded as a cloud enhancing treatment around on-premise legacy application, rather than a pure cloud enabling [32]. This type of migration requires a series of reconfigurations to adjust incompatibilities to use functionalities of the ported layer.

Type II (partially migrate) migrates some of the software system's components to the cloud [S10] [S12] [S14] [S15] [S16] [S18] [S21] [S22]. As an example, migrating only the auditing functionality of a healthcare system to the cloud can be categorized as a type II of migration.

Type III (migrate the whole application stack) is the easiest way of migration where the whole application is monolithically encapsulated in one or more virtual machines running on the cloud [S4] [S5] [S6] [S7] [S17]. This type of migration needs no adaptation assuming the application stack can be ported 'as is' into a virtual machine.

Type IV (cloudify) is the most complete migration where an application is converted to a full-fledged cloud-enabled system by composing cloud services [S1] [S2] [S3] [S8] [S9] [S11] [S13] [S19] [S20] [S23]. Type IV and II are similar, but the scope of migration in type II is limited to selected functions. As the most invasive type of migration, these two types need adaptation at the composition level such as business processes, composite services and their supporting infrastructure.

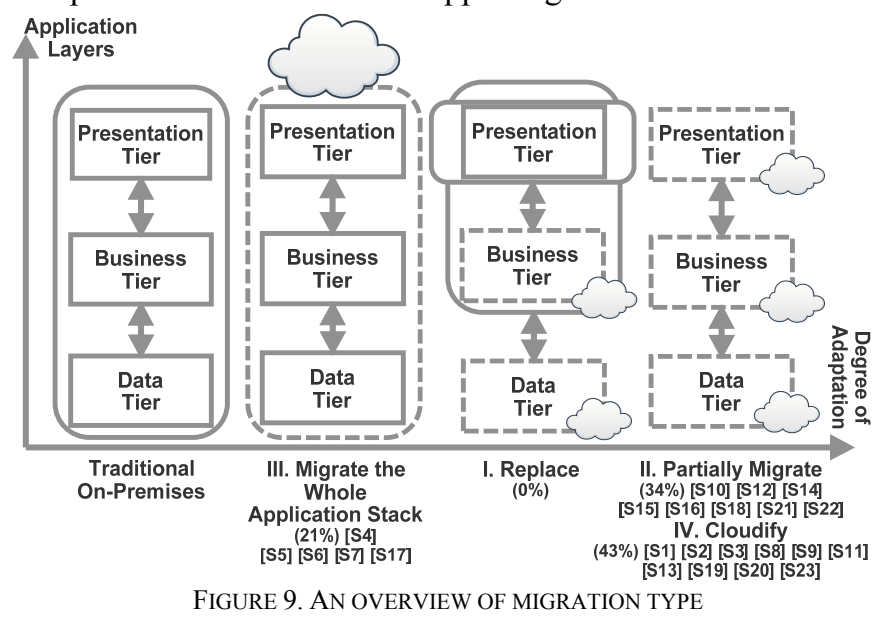

Migration type and crosscutting concerns. The four different migration types also influence crosscutting concerns differently 
[S8]. In terms of elasticity (cf. Cloud-RMM in FiguRE 4), adding more instances of applications will only influence if the application is engineered for load balancing between the resources. This capability rarely holds for type III while the other types of migration can benefit from this scalability. For a more detailed association of adaptations and crosscutting concerns to each type refer to [3].

In summary, the findings reveals that while migration type III (cf. TABLE 7) was believed to be addressed by the majority of studies [3], this assumption is not valid anymore. This is partly because migration practices have improved during the last couple of years (cf. Section VI.A). According to summarized data in FIGURE 9, migration types II and IV are the major migration types among the studies.

\section{3) Methods, techniques and tool support for cloud migration}

We answer RQ3 by exploring approaches that support cloud migration. TABLE 10, TABLE 11 and TABLE 12 present the classification of studies according to our framework. The tables are separated according to a high-level classification of studies based on means of migration. Two data items (contribution type in FiguRE 6 and intent of migration in FiguRE 8 ) out of twelve are omitted from the tables due to space limitations. Since the items related to the migration support theme are not related to experience reports, we do not consider them in TABLE 11 . Decision support in migration processes covers tasks to facilitate decision making, such as the study of migration feasibility, deciding which sub-system to be migrated or which cloud provider to choose (see TABLE 10). Migration execution comprises tasks that enable the actual migration of a legacy system. These include guidelines, processes, and model transformation and address tasks such as architecture recovery and transformation as well as evaluation of migrated systems (see TABLE 11). A summary of experience reports on cloud migration can be found in TABLE 12.

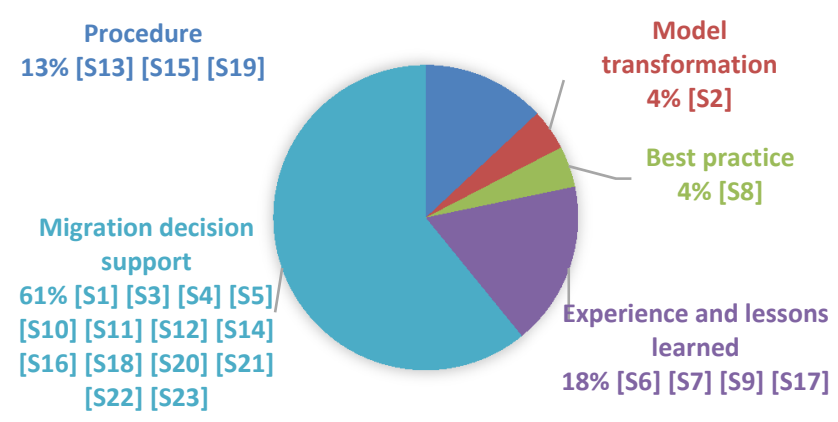

FigURE 10. CLASSIFICATION OF STUDIES ACCORDING TO THE MEANS OF MIGRATION

Cloud migration approaches range from decision making to enabling legacy software migration with approaches reporting best practice, experience and lessons learned in between. Decision making for cloud adoption [S1] [S3] [S4] [S5] [S10] [S11] [S12] [S14] [S16] [S18] [S20] [S21] [S22] [S23] is inherently complex and influenced by multiple factors such as cost and benefits through migration [33]. In contrast, some approaches enable the actual migration of legacy software in terms of procedures [S13] [S15] [S19] and model transformation [S2]. Other work [S6] [S7] [S9] [S17] report on experience and lessons learned or best practice [S8] - providing empirical evidence for migration research. According to FiguRE 10 , most studies ( $61 \%$ of studies) are approaches that investigate migration decision support.

\begin{tabular}{|c|c|c|c|c|c|c|c|c|}
\hline \multirow[b]{2}{*}{ ID } & \multicolumn{2}{|c|}{ Migration Characterization } & \multicolumn{3}{|c|}{ Constraints on Migration } & \multicolumn{2}{|c|}{ Migration Support } & \multirow{2}{*}{$\begin{array}{c}\text { Maturity } \\
\text { Evaluation } \\
\text { Method }\end{array}$} \\
\hline & $\begin{array}{l}\text { Migration } \\
\text { Task }\end{array}$ & $\begin{array}{l}\text { Migration } \\
\text { Type }\end{array}$ & $\begin{array}{l}\text { Stack } \\
\text { Layer }\end{array}$ & $\begin{array}{l}\text { Architect } \\
\text { ural Style }\end{array}$ & $\begin{array}{c}\text { Target } \\
\text { Platform }\end{array}$ & $\begin{array}{c}\text { Degree of } \\
\text { Automation }\end{array}$ & $\begin{array}{c}\text { Tool } \\
\text { Support }\end{array}$ & \\
\hline$[\mathrm{S} 1]$ & $\begin{array}{c}\text { Decision of providers, Configurations, } \\
\text { Decision of sub-systems }\end{array}$ & Cloudify & laas & $\begin{array}{c}\text { Style } \\
\text { agnostic }\end{array}$ & $\begin{array}{l}\text { Platform } \\
\text { agnostic }\end{array}$ & $\begin{array}{c}\text { Fully- } \\
\text { automated }\end{array}$ & CDOSim & $\begin{array}{c}\text { Controlled } \\
\text { Experiment } \\
\end{array}$ \\
\hline$[\mathrm{S} 3]$ & Migration validation & Cloudify & laas & $\begin{array}{c}\text { Style } \\
\text { agnostic }\end{array}$ & $\begin{array}{l}\text { Platform } \\
\text { agnostic }\end{array}$ & $\begin{array}{c}\text { Fully- } \\
\text { automated }\end{array}$ & $\begin{array}{c}\text { CloudMIG } \\
\text { Xpress }\end{array}$ & $\begin{array}{c}\text { Controlled } \\
\text { Experiment } \\
\end{array}$ \\
\hline$[S 4]$ & Decision of services & $\begin{array}{l}\text { Migrate the } \\
\text { whole stack }\end{array}$ & PaaS, laas & $\begin{array}{c}\text { Style } \\
\text { agnostic }\end{array}$ & $\begin{array}{l}\text { Platform } \\
\text { agnostic }\end{array}$ & $\begin{array}{c}\text { Semi- } \\
\text { automated }\end{array}$ & CloudGenius & $\begin{array}{c}\text { Controlled } \\
\text { Experiment }\end{array}$ \\
\hline$[\mathrm{S} 5]$ & $\begin{array}{c}\text { Decision of providers, Migration } \\
\text { strategies }\end{array}$ & $\begin{array}{l}\text { Migrate the } \\
\text { whole stack }\end{array}$ & NM & $\begin{array}{c}\text { Style } \\
\text { agnostic }\end{array}$ & $\begin{array}{l}\text { Platform } \\
\text { agnostic }\end{array}$ & Manual & -- & $\begin{array}{c}\text { Example } \\
\text { application }\end{array}$ \\
\hline [S10] & $\begin{array}{l}\text { Decision of providers, Decision of } \\
\text { sub-systems, Decision of services, } \\
\text { Migration strategies, Feasibility study }\end{array}$ & $\begin{array}{l}\text { Partially } \\
\text { migrate }\end{array}$ & PaaS, IaaS & $\begin{array}{c}\text { Style } \\
\text { agnostic }\end{array}$ & $\begin{array}{l}\text { Platform } \\
\text { agnostic }\end{array}$ & Manual & -- & Case Study \\
\hline [S11] & $\begin{array}{c}\text { Feasibility study, Decision of } \\
\text { providers, Decision of sub-systems, } \\
\text { Decision of services }\end{array}$ & Cloudify & laaS, SaaS & NM & NM & Manual & -- & $\begin{array}{l}\text { Controlled } \\
\text { Experiment }\end{array}$ \\
\hline$[\mathrm{S} 12]$ & Feasibility study & $\begin{array}{l}\text { Partially } \\
\text { migrate }\end{array}$ & NM & NM & NM & Manual & -- & $\begin{array}{l}\text { Example } \\
\text { application }\end{array}$ \\
\hline [S14] & $\begin{array}{l}\text { Requirement analysis, Decision of } \\
\text { providers }\end{array}$ & $\begin{array}{l}\text { Partially } \\
\text { migrate }\end{array}$ & NM & NM & $\begin{array}{l}\text { Platform } \\
\text { agnostic }\end{array}$ & Manual & -- & $\begin{array}{l}\text { Example } \\
\text { application }\end{array}$ \\
\hline [S16] & $\begin{array}{c}\text { Training, Configurations, Code } \\
\text { modification, Transformation, Test }\end{array}$ & $\begin{array}{l}\text { Partially } \\
\text { migrate }\end{array}$ & NM & NM & NM & Manual & -- & $\begin{array}{c}\text { Controlled } \\
\text { Experiment }\end{array}$ \\
\hline [S18] & Effort estimation & $\begin{array}{l}\text { Partially } \\
\text { migrate }\end{array}$ & PaaS, IaaS & $\mathrm{OO}$ & $\begin{array}{l}\text { Platform } \\
\text { agnostic }\end{array}$ & Manual & -- & $\begin{array}{l}\text { Mathemati } \\
\text { cal Proof }\end{array}$ \\
\hline [S20] & Migration validation & Cloudify & PaaS, IaaS & $\begin{array}{c}\text { Style } \\
\text { agnostic }\end{array}$ & $\begin{array}{l}\text { Platform } \\
\text { agnostic }\end{array}$ & $\begin{array}{c}\text { Fully- } \\
\text { automated }\end{array}$ & $\begin{array}{c}\text { CloudMIG } \\
\text { Xpress }\end{array}$ & $\begin{array}{c}\text { Controlled } \\
\text { Experiment }\end{array}$ \\
\hline [S21] & Feasibility study & $\begin{array}{l}\text { Partially } \\
\text { migrate }\end{array}$ & NM & $\begin{array}{c}\text { Style } \\
\text { agnostic }\end{array}$ & $\begin{array}{l}\text { Platform } \\
\text { agnostic }\end{array}$ & $\begin{array}{l}\text { Semi- } \\
\text { automated }\end{array}$ & $\begin{array}{l}\text { Cloud } \\
\text { Adoption } \\
\text { Toolkit }\end{array}$ & Case Study \\
\hline [S22] & $\begin{array}{c}\text { Decision of sub-systems, Security } \\
\text { analysis }\end{array}$ & $\begin{array}{l}\text { Partially } \\
\text { migrate }\end{array}$ & PaaS, IaaS & $\begin{array}{c}\text { Style } \\
\text { agnostic }\end{array}$ & $\begin{array}{l}\text { Platform } \\
\text { agnostic }\end{array}$ & $\begin{array}{c}\text { Fully- } \\
\text { automated }\end{array}$ & $\begin{array}{c}\text { Cloudward } \\
\text { Bound }\end{array}$ & $\begin{array}{c}\text { Controlled } \\
\text { Experiment }\end{array}$ \\
\hline [S23] & $\begin{array}{l}\text { Decision of providers, Decision of } \\
\text { services, Architecture adaptation }\end{array}$ & Cloudify & laas & $\begin{array}{c}\text { Style } \\
\text { agnostic }\end{array}$ & $\begin{array}{l}\text { Platform } \\
\text { agnostic }\end{array}$ & $\begin{array}{c}\text { Fully- } \\
\text { automated }\end{array}$ & CDOXplorer & $\begin{array}{c}\text { Controlled } \\
\text { Experiment }\end{array}$ \\
\hline
\end{tabular}




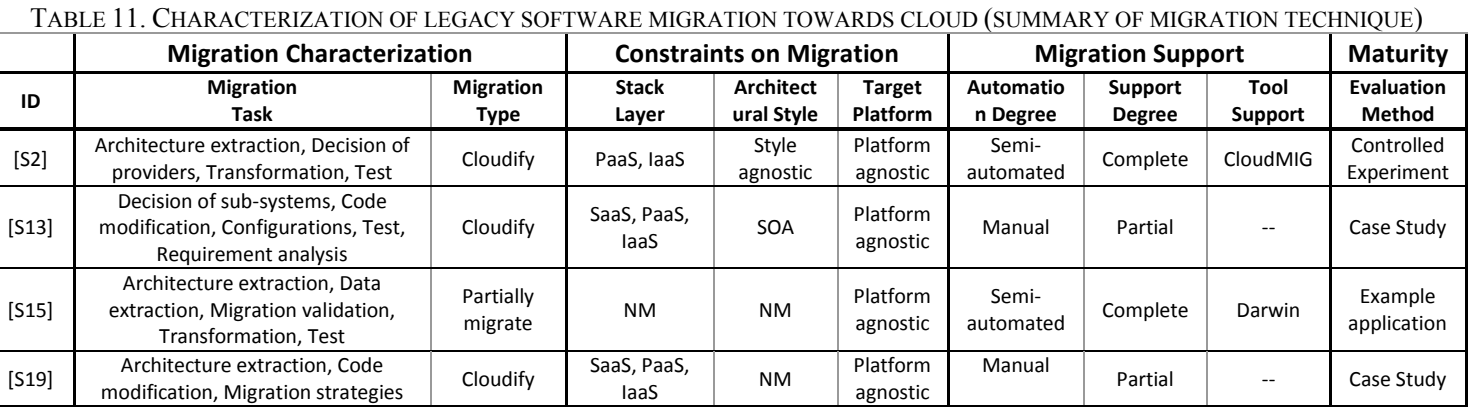

Migration decision support. By synthesizing TABLE 10, the following observations can be made. Decision of providers, feasibility study, decision of cloud services, and decision of subsystems to be migrated are the relevant migration tasks in migration decision support. Migration type IV (i.e., cloudify) represent a minority type in this migration class. A fair percentage of the studies in this class (i.e., 50\%) have some degree of automation. $57 \%$ of the studies used controlled experiments to support their claims about migration and only $21 \%$ of studies used only small-scale toy example.

Migration techniques. According to TABLE 11, only four studies are categorized as enabling cloud migration. Within this class, architecture extraction, test, code modification and transformation are the most common migration tasks. As opposed to the previous category, type IV migration is not a minority. All primary studies are generic (i.e., style and platform agnostic and applicable to all cloud types) according to the constraint on migration. Half of the studies in this category provide tool support and claim that they support the full migration lifecycle. In terms of the maturity of the approaches, all except one of the studies either provide case studies or performed control experiments to support claims.

Experience and lessons learned. According to TABLE 12, five studies report experiences and lessons learned as well as best practices. In this class of migration, architecture extraction is a popular migration task. As expected, this constrains their approach to specific cloud-based environments. In terms of maturity level, three types of evaluation methods including case study, experiment and survey are employed.

TABLE 12. CHARACTERIZATION OF LEGACY SOFTWARE MIGRATION TOWARDS CLOUD (SUMMARY OF EVALUATION RESEARCH AND EXPERIENCE REPORTS)

CLOUD (SUMMARY OF EVALUATION RESEARCH AND EXPERIENCE REPORTS)
\begin{tabular}{|c|c|c|c|c|c|c|}
\hline & \multicolumn{2}{|c|}{ Migration Characterization } & \multicolumn{3}{c|}{ Constraints on Migration } & Maturity \\
\hline ID & $\begin{array}{c}\text { Migration } \\
\text { Task }\end{array}$ & $\begin{array}{c}\text { Migration } \\
\text { Type }\end{array}$ & $\begin{array}{c}\text { Stack } \\
\text { Layer }\end{array}$ & $\begin{array}{c}\text { Architectural } \\
\text { Style }\end{array}$ & $\begin{array}{c}\text { Target } \\
\text { Platform }\end{array}$ & $\begin{array}{c}\text { Evaluation } \\
\text { Method }\end{array}$ \\
\hline$[56]$ & $\begin{array}{c}\text { Training, Architecture extraction, Data } \\
\text { extraction, Decision of services, Test }\end{array}$ & $\begin{array}{c}\text { Migrate the whole } \\
\text { software stack }\end{array}$ & NM & NM & NM & Case Study \\
\hline$[57]$ & Training, Migration strategies & $\begin{array}{c}\text { Migrate the whole } \\
\text { software stack }\end{array}$ & laas & NM & Amazon EC2 & Case Study \\
\hline$[58]$ & $\begin{array}{c}\text { Data extraction, Architecture } \\
\text { extraction, Requirement analysis, } \\
\text { Security analysis, feasibility study }\end{array}$ & cloudify & $\begin{array}{c}\text { Saas, Paas, } \\
\text { laas }\end{array}$ & Style agnostic & $\begin{array}{c}\text { Platform } \\
\text { agnostic }\end{array}$ & Survey \\
\hline$[59]$ & Decision of services & Cloudify & laas & NM & Eucalyptus 2.0 & $\begin{array}{c}\text { Controlled } \\
\text { Experiment }\end{array}$ \\
\hline$[517]$ & $\begin{array}{c}\text { Requirement analysis, Architecture } \\
\text { extraction, Test, Security analysis }\end{array}$ & $\begin{array}{c}\text { Migrate the whole } \\
\text { software stack }\end{array}$ & Saas, laas & NM & NM & Case Study \\
\hline
\end{tabular}

Automated support usually reduces migration efforts and therefore is often an aim. Tool support can also provide an appropriate basis for studies to back up claims through controlled experiments. According to TABLE 13, nine studies (i.e., $39 \%$ ) provide a degree of automation. Five studies [S1] [S3] [S20] [S22] [S23] provide full automation for cloud migration approaches they are presenting. For example, [S20] is a fully automated approach for conformance checking in cloud migration with the assistance of constraint validators. In another set of four studies [S2] [S4] [S15] [S21], there were both manual and automated aspects. The provided automated support in general facilitates either measuring a metric for decision support or transforming an architectural model for migration. The techniques in ten studies [S5] [S10] [S11] [S12] [S13] [S14] [S16] [S17] [S18] [S19] were fully manual. For instance, [S18] presented a methodology for estimating the size of cloud migration projects based on function points, in which the data for model estimation had to be manually provided. The remaining four studies [S6] [S7] [S8] [S9] were not directly involved with specific solutions, but with other aspects of research such as evaluation and experience.

TABLE 13. DisTRIBUTION OF STUDIES ACCORDING TO AUTOMATION DEGREE

\begin{tabular}{|l|l|}
\hline Automation level & \multicolumn{1}{c|}{ Studies } \\
\hline Fully-automated & {$[\mathrm{S} 1][\mathrm{S} 3][\mathrm{S} 20][\mathrm{S} 22][\mathrm{S} 23]$} \\
\hline Semi-automated & {$[\mathrm{S} 2][\mathrm{S} 4][\mathrm{S} 15][\mathrm{S} 21]$} \\
\hline \multirow{2}{*}{ Manual } & {$[\mathrm{S} 5][\mathrm{S} 10][\mathrm{S} 11][\mathrm{S} 12][\mathrm{S} 13]$} \\
& {$[\mathrm{S} 14][\mathrm{S} 16][\mathrm{S} 17][$ S18] [S19] } \\
\hline
\end{tabular}

\section{RESEARCH IMPLICATIONS AND FUTURE DIMENSIONS}

We have presented a systematic review to analyze the collective coverage and impact of research that enables or enhances cloud migration. We classified and compared existing work in Section $\mathrm{V}$ to answer the first three research questions (RQ1-3). We now address RQ4. We first discuss the maturity level of research in Section VI.A, after which we summarize research progress and principle findings to highlight trends and possible future research. Finally, we look at the key benefits of this study for researchers and practitioners in cloud migration in Section VI.C.

\section{A. Maturity of cloud migration research}

We show an overview of evidence gathered from the analysis of cloud migration in three different facets in Figure 11. The research facet has options connected to the contribution type, the contribution facet refers to options associated to means of migration and the evaluation facet relates to evaluation method options. We used a bubble plot to represent the frequencies of studies on interconnections of facets. This is an $x-y-z$ scatterplot with bubbles in category intersections. The size of a bubble is proportional to the number of studies that are in the pair of categories corresponding to the bubble coordinates. For instance, the intersection between solution proposal and migration decision support can be interpreted as follows. There are 12 articles out of 23 where the contribution type is a specific 
solution technique; its means of migration is meant to support decision making in a migration process. We use this map to discuss the maturity of cloud migration based on our systematic review.

As FIGURE 11 shows, there are contributions to cloud migration research primarily proposing migration decision support. To date, a controlled experiment is the most adopted evaluation method, but there are also 11 studies that utilize case studies or small examples for evaluation. Some methods are rarely used, e.g., experience report, mathematical proof and survey. FIGURE 11 also indicates that the field is in a formative stage experience report and evaluation research that determine cloud migration applicability in an industrial context are lacking. However, we retrieved a number of whitepapers and technical reports that are adopted in industry, but since they lack scientific rigor, we excluded them from this review. Only few tools have been proposed, largely at validation stage and not in large-scale use yet. There is a lack of validation research and philosophical papers, which implies that the field is not moving toward a broader cloud computing community's interest.

\section{B. Research trend and future directions}

After synthesizing data collected through this SLR, we observed a number of research trends and found a number of research challenges that are not addressed properly and represent the potential future directions.

The growing maturity level. Although we observed that the maturity of cloud migration is in a formative stage, however, we can note a clear growth in maturity. As another sign of improvement, all types of migration as discussed in Section V.B.2) are reported in the literature. We can conclude that conducting validation research across all types of contributions is an area that still needs attention. In addition, more research results on cloud migration evaluation with realworld case studies and experience reports is needed. More case studies will result in more confidence of researchers and practitioners regarding the benefits of cloud migration and the validity of research. One dimension that is a future direction for cloud migration studies is the importance of open accessible results specifically for migration decision support research. This helps to replicate experiments and leads to making general conclusions about the migration practices.

The needs for a comprehensive migration framework. We provided a reference model in Section IV.A. However, the research community needs to propose a cloud migration framework such as the ones that we reviewed in Section III for SOA migration with concrete evidence of solutions in terms of methods and techniques supporting the process areas. A migration framework defines a systematic process to perform the migration while evidence defines concrete tasks, methods and techniques. Such a concrete framework would constitute an important contribution towards a systematic migration.

Solutions to address crosscutting concerns. According to FIGURE 4, the primary focus of the studies is on migration planning (16 studies), while crosscutting concerns (seven studies for six tasks) have received relatively limited attention. There is also relatively little work on migration execution (eight studies) and migration evaluation (nine studies) in comparison with migration planning. By analyzing data in FIGURE 4, seven studies [S2] [S6] [S8] [S13] [S17] [S19] [23] cover migration planning and execution and six studies [S2] [S6] [S8] [S13] [S15] [S17] cover migration execution and evaluation. Only two studies ([S6] [S8]) cover all processes comprehensively. This indicates a lack of comprehensive evidence for tasks and methods to support the migration framework above. Therefore, research regarding crosscutting concerns covering all processes can be considered as a future dimension for cloud migration.

Automated support in migration process. An observation we made relates to the automation degree in migration processes. Although a full-automated solution is not feasible, users can customize and guide the migration process supported by a toolset. According to TABLE 13, nine studies [S1] [S2] [S3] [S4] [S15] [S20] [S21] [S22] [S23] have a degree of automation. However, only three of them [S2] [S15] [S23] are related to the migration execution (cf. FIgURE 4). This confirms a lack of tools for migration execution and is a task for the future.

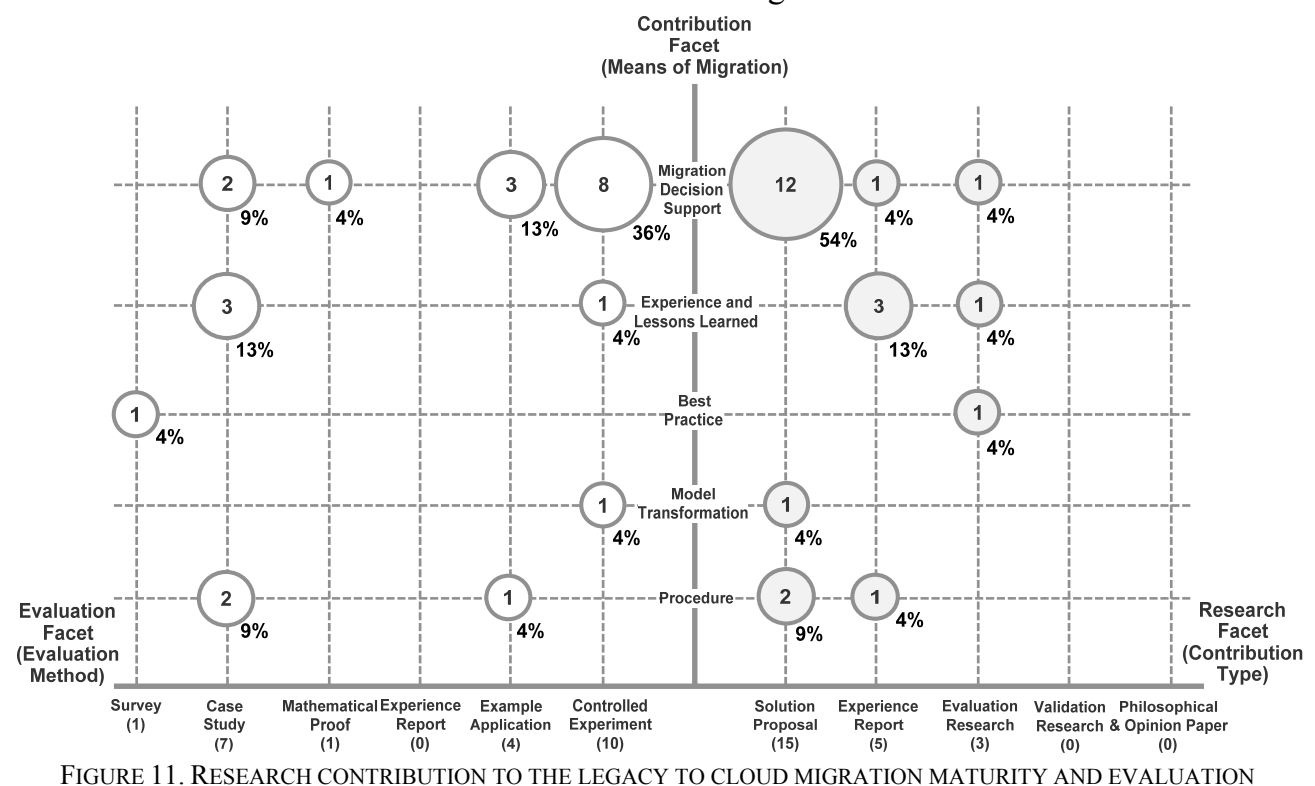

FIGURE 11. RESEARCH CONTRIBUTION TO THE LEGACY TO CLOUD MIGRATION MATURITY AND EVALUATION 
The needs for architectural adaptation support. In the context of cloud migration, different layers of software cannot be considered isolated from each other. More concretely adapting business processes, for example, to move parts to the cloud, may affect underlying services and supporting infrastructure as well as the data layer [3]. This inter-layer adaptation is an open issue [3], inferred based on the lack of studies (only [S8] [S23]) focusing on architectural adaptations in this review. Thus, there is a need for systematic architectural support for adaptation purposes during cloud migration. As an example, the logical separation between the cloud service providers and the applications, the agreed contract between them is one of the distinguishing aspect of cloud applications that need to be supported by architecture description - see [34] as an initial attempt toward cloud application architectures. We believe that the notion of migration path as a sequence of transitional architectures and tools supporting the architect to select the best path based on constraints and goals is promising direction. A similar notion of an evolution path and corresponding tool support has been proposed in [35] - see [14] for a comprehensive classification and comparison.

The needs for self-adaptive cloud-enabled systems. Multitenancy refers to a design principle of cloud architecture where a single instance of the application running on a computing facility on the cloud serves multiple tenants that reside in different organizations. Since cloud applications are designed to support multi-tenancy, they face more different contexts in comparison with on-premise applications. As a result, cloud resource consumption for cost-saving purposes has to be adapted to varying contextual conditions. Furthermore, due to the dynamics of the environments, self-managed dynamic adaptations must be performed according to changes in the environment in order to meet non-functional requirements, such as replacing a cloud service that is being used by another one in case of a degradation of quality parameters or when new services arise in the environment [34]. However, only one study [S23] considers run-time adaptation for dynamic resource scaling during migration.

\section{Benefits for researchers and practitioners}

The characterization framework (Section IV) provides a holistic view of different migration aspects to be considered in the context of the migration process. The classification and comparison of studies through this framework, which contains 12 comparison attributes, provides a reasonable amount of information. For instance, for the 23 papers and 12 comparison attributes, it creates a collection with $23 * 12=276$ data points. As a result, the user can query and analyze the knowledge base to choose a migration strategy based on his requirements, e.g., <Subject: Legacy to Cloud Migration> [Object: using Model Transformation] (Type of Environment: IaaS, Architectural Style: Style-agnostic, Target Platform: platform agnostic). This is beneficial for researchers who require a quick identification of relevant studies and detailed insight into state-of-the-art that supports cloud migration, but also for practitioners interested in understanding existing methods for migration decision support or legacy migration.
When choosing a method for migration, a variety of aspects comes into play [23]. Examples are enterprise-level aspects including the type of company that owns the software or users of the system [24]. Moreover, technical support comprising cloud vendors, independent consultants or system integrators as well as the IT artefacts involved in the migration. This might be the case if two or more migration strategies are combined to achieve the required goal depending on advantages and disadvantages of each method in specific contexts. Evidence of this is demonstrated in [24]. However, it is not always straightforward to reuse legacy components and expose them as e.g., SaaS services. This might impose a higher risk for business critical systems and a higher cost for enterprise systems than replacing them entirely with a cloud-native application [23].

In summary, there is no single solution to the problem of migration a legacy system to the cloud. The choice of method for migration depends on the goals, the available budget and resources and the time needed to complete the project [23].

\section{THREATS TO VALIDITY}

This SLR provides a classification and comparison of cloud migration approaches. Although the results of systematic reviews are reliable in general [36], this type of review work has potential limitations [8]. We discuss threats to the validity of this work in different steps in our SLR (cf. FIGURE 1).

Threats to the identification of primary studies. In our search strategies, the key idea was to retrieve as much as possible of the available literature to avoid any bias. Another challenge in addressing these threats was to determine the scope of our study, since cloud migration relates to different communities including software engineering, information systems and networks. These communities use different terminologies for the same concepts. To cover all and avoid bias, we searched for common terms and combined them in our search string. While this approach decreases bias, it significantly increases search work. To identify relevant studies and ensure the process of selection was unbiased, a review protocol was developed.

Threats to selection and data extraction consistency. In SLRs, each study is subjected to a quality assessment [8]:

- Result bias - A tendency to produce results that deviate systematically from the 'true' results. Unbiased results are internally valid.

- Internal validity - The extent to which the design and conduct of the study are likely to prevent systematic error.

- External validity - The extent to which the effects observed are applicable outside of the study context.

We used two kinds of quality assessment (Section III.B). The first kind intended to assess the quality of the papers with respect to their ability and suitability to answer our research questions, with respect to the impact on the drawn conclusions (general items in TABle 6. Quality assessment CheCKList). The second type served as an instrument to answer one of our main research questions (specific items in TABLE 6. QUALITY ASSESSMENT CHECKLIST). In a systematic review, the main purpose of quality assessment is to assess the impact of the quality of the primary studies on the conclusions drawn, e.g., if the quality of primary 
studies is low, the conclusions based on these studies are unlikely to be strong and reliable.

Threats to data synthesis and results. Another challenge of reviews is the reliability threat. This is mitigated as far as possible by involving multiple researchers, having a unified characterization scheme, and several steps where scheme and process were piloted and externally evaluated. Although we were determined to use the guidelines provided in [8] to perform our systematic review, we had deviations from their procedures as we described in detail in Section III.

We can conclude that the validity of the study is high, given the use of a systematic procedure and the involvement of different researchers and external evaluations. The openness of our review by exposing our data in [11] allows researchers to judge the result's trustworthiness objectively.

\section{CONCLUSIONS}

The objective of this study was to consolidate existing research on legacy software migration to the cloud regarding the claimed benefits and the provided evidence of migration. The main contribution of this study is a characterization framework for cloud migration and a comparison of systematically selected studies through the framework to point out existing research gaps. We identified unexplored areas by synthesizing collected data, reflecting on areas of future research. The results of classification and comparison are presented as structure tables and visual diagrams - as a means to transfer knowledge among cloud computing researchers and practitioners about a collective impact of existing research.

We have extracted the core migration processes with specific tasks to define cloud migration reference model - Cloud-RMM:

- Planning: feasibility study, requirements analysis, decisions of providers and services, migration strategies

- Execution: code modification, architecture extraction, data extraction and transformation

- Evaluation: deployment, testing, validation

- Crosscutting concerns: governance, security, training, effort estimation, organizational change, multi-tenancy

Section V.B.3) has in detail identified methods and techniques used. This allows comparing and differentiating cloud from SOA migration, which becomes evident in terms of the need to consider a layered cloud stack or the importance of specific targeted platforms or the different configuration of the migration process stages, where particularly the migration execution requires techniques different from SOA that establishes cloud migration as a concern in its own right.

The field is still in a formative stage, but stabilizing. We identified a need for a concrete migration framework to enable systematic migration to the cloud. Our study indicates that crosscutting concerns are not adequately addressed. We also observed a lack of tool support for enhancing cloud migration. An interesting observation also indicates a lack of evidence for architectural adaptation support and self-adaptive cloud systems. We believe that in order to mature the field further, cloud computing and software engineering researchers need to propose a common research agenda.

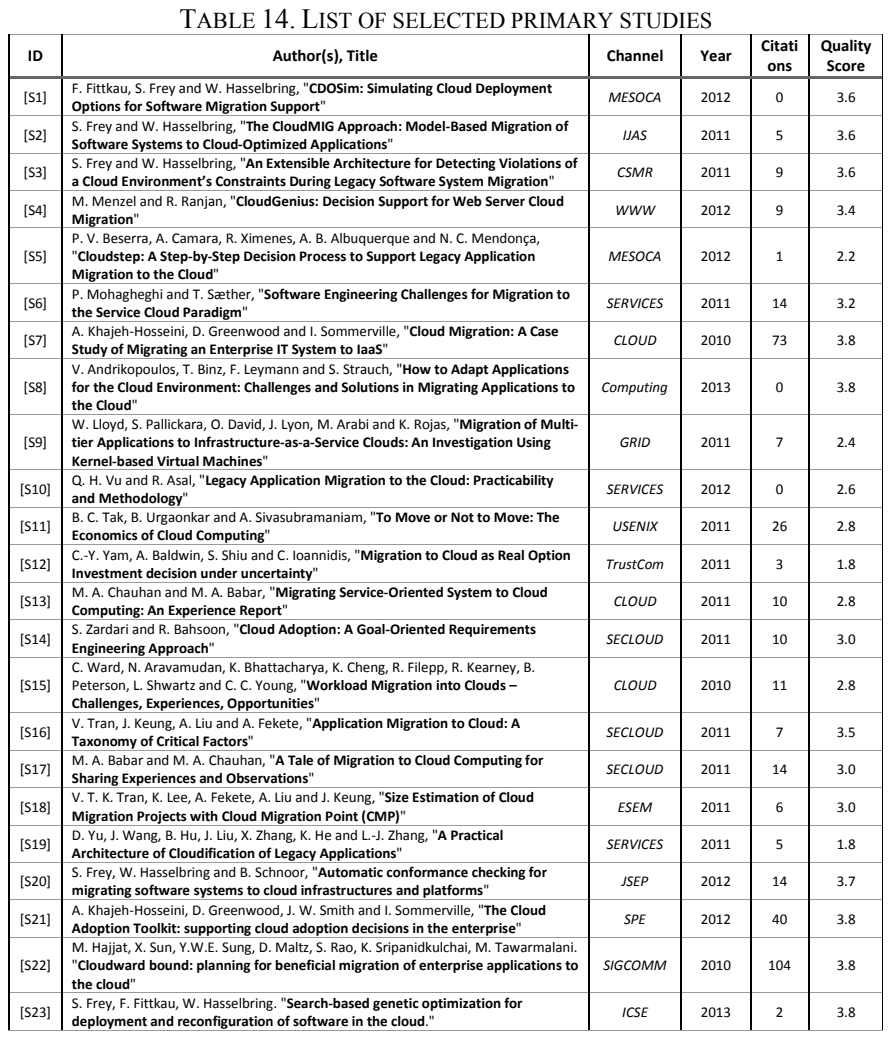

\section{ACKNOWLEDGMENT}

The research work described in this paper was partly supported by the Irish Centre for Cloud Computing and Commerce, a national technology centre funded by Enterprise Ireland and the Irish Industrial Development Authority. This work was also supported, in part, by Science Foundation Ireland grant 10/CE/I1855 to Lero - the Irish Software Engineering Research Centre (www.lero.ie).

\section{REFERENCES}

[1] M. Armbrust, A. Fox, R. Griffith, A. D. Joseph, R. Katz, A. Konwinski, G. Lee, D. Patterson, A. Rabkin, I. Stoica and M. Zaharia, "A view of cloud computing," Communications of the ACM, vol. 53, no. 4, pp. 50-58, 2010.

[2] R. Buyya, C. S. Yeo, S. Venugopal, J. Broberg and I. Brandic, "Cloud computing and emerging IT platforms: Vision, hype, and reality for delivering computing as the 5th utility," Future Generation computer systems, vol. 25, no. 6, pp. 599-616, 2009.

[3] V. Andrikopoulos, T. Binz, F. Leymann and S. Strauch, "How to Adapt Applications for the Cloud Environment: Challenges and Solutions in Migrating Applications to the Cloud," Computing, vol. 95, no. 6, pp. 493535, 2013.

[4] A. Khajeh-Hosseini, D. Greenwood, J. W. Smith and I. Sommerville, "The Cloud Adoption Toolkit: supporting cloud adoption decisions in the enterprise," Software - Practice and Experience, vol. 42, p. 447-465, 2012.

[5] V. Tran, J. Keung, A. Liu and A. Fekete, "Application Migration to Cloud: A Taxonomy of Critical Factors," in Proceedings of the 2nd International Workshop on Software Engineering for Cloud Computing, 2011.

[6] R. Khadka, A. Saeidi, A. Idu, J. Hage and S. Jansen, "Legacy to SOA Evolution: A Systematic Literature Review," in Migrating Legacy Applications: Challenges in Service Oriented Architecture and Cloud Computing Envioronment, IGI, 2013.

[7] S. Frey and W. Hasselbring, "The CloudMIG Approach: Model-Based Migration of Software Systems to Cloud-Optimized Applications," International Journal on Advances in Software, pp. 342-353, 2011. 
[8] P. Brereton, B. A. Kitchenham, D. Budgen, M. Turner and M. Khalil, "Lessons from Applying the Systematic Literature Review Process within the Software Engineering Domain," Journal of systems and software, vol. 80, no. 4, pp. 571-583, 2007.

[9] M. Petticrew and H. Roberts, Systematic reviews in the social sciences: A practical guide, Wiley-Blackwell, 2008.

[10] B. Kitchenham and S. Charters, "Guideline for Performing Systematic Literature Reviews in Software engineering," Keele University and University of Durham, 2007.

[11] P. Jamshidi, A. Ahmad and C. Pahl, "Cloud Migration Research: A Systematic Literature Review [Data]," 2013. [Online]. Available: http://www.computing.dcu.ie/ pjamshidi/SLR/SLR-CM.html.

[12] R. Wieringa, N. Maiden, N. Mead and C. Rolland, "Requirements engineering paper classification and evaluation criteria: a proposal and a discussion," Requirements Engineering, vol. 11, no. 1, pp. 102-107, 2006.

[13] P. Jamshidi, M. Ghafari, A. Ahmad and C. Pahl, "A Framework for Classifying and Comparing Architecture Centric Software Evolution Research," in 17th European Conference on Software Maintenance and Reengineering (CSMR), Genova, 2013.

[14] A. Aakash, P. Jamshidi and C. Pahl, "A Classification and Comparison of Software Architecture Evolution Reuse-Knowledge," 2013. [Online]. Available: http://www.computing.dcu.ie/ pjamshidi/SLR/SLR-ERK.html.

[15] G. A. Lewis, D. B. Smith and K. Kontogiannis, "A research agenda for service-oriented architecture (SOA): Maintenance and evolution of serviceoriented systems," SEI, 2010.

[16] R. Balasubramanian, "How SOA and the Cloud Relate," Dec 2009. [Online] Available: http://tinyurl.com/mqtjfct.

[17] T. Binz, G. Breiter, F. Leyman and T. Spatzier, "Portable cloud services using tosca," Internet Computing, vol. 16, no. 3, pp. 80-85, 2012.

[18] S. Mansfield-Devine, "Danger in the clouds," Network Security, vol. 12, pp. 9-11, 2008.

[19] M. F. Gholami, M. Sharifi and P. Jamshidi, "Enhancing the OPEN Process Framework with service-oriented method fragments," Software \& Systems Modeling, pp. 1-30, 2011.

[20] ISO/IEC, "Systems and software engineering- Software life cycle processes Maintenance," ISO/IEC, ISO/IEC 14764:2006.

[21] M. Razavian and P. Lago, "A survey of SOA migration in industry," ServiceOriented Computing, pp. 618-626, 2011.

[22] M. Razavian and P. Lago, "A frame of reference for soa migration," Towards a Service-Based Internet, pp. 150-162, 2010.

[23] A. A. Almonaies, J. R. Cordy and T. R. Dean, "Legacy system evolution towards service-oriented architecture," in International Workshop on SOA Migration and Evolution, 2010.

[24] C. Pahl, H. Xiong and R. Walshe, "A Comparison of On-premise to Cloud Migration Approaches - A Tale of Four Cloud Migration Processes," in European Conference on Service-Oriented and Cloud Computing , 2013.

[25] M. Razavian and P. Lago, "Towards a Conceptual Framework for Legacy to SOA Migration," Service-Oriented Computing, pp. 445-455, 2009.

[26] G. Lewis, E. Morris, L. O'Brien, D. Smith and L. Wrage, "SMART: The service-oriented migration and reuse technique," SEI, 2005.

[27] R. Kazman, S. G. Woods and S. J. Carrière, "Requirements for integrating software architecture and reengineering models: CORUM II," in Fifth Working Conference on Reverse Engineering, 2998.

[28] S. Brinkkemper, "Method engineering: engineering of information systems development methods and tools," Information and software technology, vol. 38, no. 4, pp. 275-280, 1996.

[29] P. Mell and T. Grance, "The NIST definition of cloud computing," NIST special publication, 2011.

[30] C. I. Forum, "Cloud UK, paper one, adoption and trends," 2011. [Online]. Available: http://tinyurl.com/3f3dqba. [Accessed June 2013].

[31] C. I. Forum, "USA Cloud Adoption and Trends," 2012. [Online]. Available: http://tinyurl.com/lrpka5c. [Accessed 23 June 2013].

[32] T. Erl, Z. Mahmood and R. Puttini, Cloud Computing: Concepts, Technology \& Architecture, Prentice Hall, 2013.

[33] S. C. Misra and A. Mondal, "Identification of a company's suitability for the adoption of cloud computing and modelling its corresponding Return on Investment," Mathematical and Computer Modelling, vol. 53, no. 3, pp. 504$521,2011$.
[34] E. Cavalcante, A. L. Medeiros and T. Batista, "Describing Cloud Applications Architectures," Software Architecture, vol. 7957, pp. 320-323, 2013.

[35] J. M. Barnes, A. Pandey and D. Garlan, "Automated Planning for Software Architecture Evolution," 2013.

[36] H. Zhang and M. A. Babar, "Systematic Reviews in Software Engineering: An Empirical Investigation," Information and Software Technology (IST), vol. 55, no. 7, p. 1341-1354, 2013.

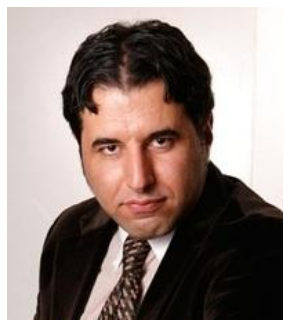

Pooyan Jamshidi is a Ph.D. candidate in the School of Computing, Faculty of Engineering and Computing at Dublin City University. He received the B.S. and M.S. degrees in computer science and systems engineering from Amirkabir University of Technology (Tehran Polytechnic), in 2003 and 2006. Pooyan is currently with IC4 - The Irish Centre for Cloud Computing and Commerce. His general research interests are in the field of software engineering and his focus lies predominantly in the areas of software architecture, software evolution and selfadaptive software. He is a reviewer for five software engineering journals and conferences.

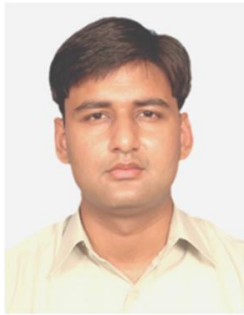

Aakash Ahmad is a Ph.D. candidate in Software Engineering at Lero - the Irish Software Engineering Research Centre, Dublin City University, Ireland. He received his B.Sc. in Software Engineering from International Islamic University Islamabad, Pakistan. He has worked as a tutor in Dublin City University, Ireland and as a Software Engineer at Elixir Technologies, Pakistan. His research interests include architecture-centric software evolution, and acquisition and application of reuse knowledge and expertise to evolve software systems.

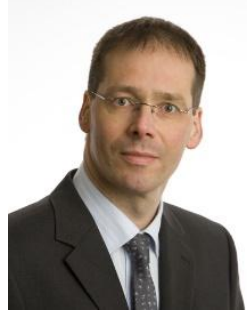

Dr. Claus Pahl is a Senior Lecturer at the School of Computing at Dublin City University. He is the Architecture Theme Lead at the national Cloud Computing Technology Centre IC4. His research focuses on Software Architecture and Cloud Service Engineering. His specific interests include Dynamic Architectures (dynamic context-dependent composition, service models at runtime; constraints monitoring), Business Process and Service Architecture Integration (layered architectures for process and architecture configuration); and Mediation and Integration in Cloud Computing (interoperability for on-demand architectures; multi-tenancy SOA and policy-based governance). Claus has published more than 240 papers. He is a reviewer for more than 30 journals and helped organizing more than 100 conferences and workshops. He is on the editorial board of four journals and he has acted as panel member and evaluator for various research schemes worldwide. 